\title{
ACCOUNTING FOR DISABILITY INSURANCE IN THE DYNAMIC RELATIONSHIP BETWEEN DISABILITY ONSET AND EARNINGS
}

\author{
Perry Singleton
}

CRR WP 2010-19

Date Submitted: October 2010

Date Released: November 2010

\author{
Center for Retirement Research at Boston College \\ Hovey House \\ 140 Commonwealth Avenue \\ Chestnut Hill, MA 02467 \\ Tel: 617-552-1762 Fax: 617-552-0191 \\ http://crr.bc.edu
}

Perry Singleton is an assistant professor of Economics at Syracuse University (SU) and a senior research associate at the Center for Policy Research. The research reported herein was pursuant to a grant from the U.S. Social Security Administration (SSA) funded as part of the Retirement Research Consortium (RRC). The findings and conclusions expressed are solely those of the authors and do not represent the opinions or policy of SSA, any agency of the federal government, the RRC, SU, or Boston College. The author would like to thank Susan Chen, Jeffrey Kubik, Tim Moore, and David Pattison for helpful comments and suggestions. The author would also like to thank Paul Davies and Thuy Ho for arranging access to the data.

(C) 2010, by Perry Singleton. All rights reserved. Short sections of text, not to exceed two paragraphs, may be quoted without explicit permission provided that full credit, including $(\subset$ notice, is given to the source. 


\title{
About the Center for Retirement Research
}

The Center for Retirement Research at Boston College, part of a consortium that includes parallel centers at the University of Michigan and the National Bureau of Economic Research, was established in 1998 through a grant from the Social Security Administration. The Center's mission is to produce first-class research and forge a strong link between the academic community and decision makers in the public and private sectors around an issue of critical importance to the nation's future. To achieve this mission, the Center sponsors a wide variety of research projects, transmits new findings to a broad audience, trains new scholars, and broadens access to valuable data sources.

\author{
Center for Retirement Research at Boston College \\ Hovey House \\ 140 Commonwealth Avenue \\ Chestnut Hill, MA 02467 \\ phone: 617-552-1762 fax: 617-552-0191 \\ e-mail: crr@bc.edu \\ http://crr.bc.edu/
}

Affiliated Institutions:

The Brookings Institution

Massachusetts Institute of Technology

Syracuse University

Urban Institute 


\begin{abstract}
Policy Abstract
The onset of a work-limiting disability coincides with an immediate decline in earnings with little recovery. This study examines whether this relationship is attributable to the labor disincentives of disability insurance. The data come from the Survey of Income and Program Participation linked to administrative data from the Social Security Administration. The analysis suggests that disability insurance accounts for little of the initial drop in earnings at the time of disability onset, but its effect may increase as time since disability onset elapses. The results highlight the advantages of immediate, though temporary disability benefits.
\end{abstract}




\section{Introduction}

The dynamic relationship between disability onset and earnings is well documented in the literature, but the mechanisms responsible for this relationship remain unknown. ${ }^{1}$ Several recent studies show that, longitudinally, the onset of a work-limiting disability coincides with an immediate decline in earnings with little recovery (Charles 2003; Mok, Meyer, Charles, and Achen 2008; Meyer and Mok 2008). Because earnings decline discretely, this relationship has been largely attributed to the causal effect of health on earnings. ${ }^{2}$

Another possible mechanism, and the focus of this study, is the labor disincentives of disability insurance. The Social Security Administration (SSA) provides disability insurance through two programs: the Social Security Disability Insurance (SSDI) program and Supplemental Security Income (SSI). One criterion for benefit eligibility is the inability to engage in substantial, gainful activity, which, in 2010, is the capacity to earn more than $\$ 1,000$ per month. Because the criterion is defined by earnings, recently disabled individuals attempting to qualify for benefits may decrease earnings beyond the effect of the disability itself. A large body of literature measures the effect of disability insurance on labor supply more generally, ${ }^{3}$ but no study considers the extent to which insurance explains the dynamic relationship between health and earnings. This study aims to address this gap.

The data for the study come from a unique match of survey data to administrative data maintained by the SSA. The survey data come from several pooled panels of the Survey of Income and Program Participation (SIPP), which contain retrospective information on worklimiting disabilities. These data are matched to administrative data on longitudinal earnings, dates of disability application and receipt, and dates of death. The match data are unique, as no other data source contains information on disability onset, longitudinal earnings, and disability insurance behavior. Similar to previous studies, the analysis is limited to males.

\footnotetext{
${ }^{1}$ Currie and Madrian (1999) provide a review of the literature on health and labor market outcomes.

${ }^{2}$ Another mechanism, and the subject of much research, is justification bias: individuals justify low labor market outcomes by reporting poor health, biasing upward the effect of health and earnings. However, this bias is somewhat mitigated by a downward bias due to measurement error in health (Bound 1991).

${ }^{3}$ Studies in this literature include Parsons (1980); Bound (1989); Borsch-Supan (2000); Gruber (2000); Black, Daniel, and Sanders (2002); Autor and Duggan (2003); Duggan, Singleton, and Song (2007); and Duggan, Rosenheck, and Singleton (2010).
} 
Retrospective data on work-limiting disabilities, combined with data on longitudinal earnings, show that earnings decrease precipitously at the time of disability onset and that the decrease is greater among the more severely disabled. These patterns, consistent with those found in related literature, suggest a large, causal effect of health on earnings. Using data on disability insurance, disability onset also coincides with sharp increases in disability application and receipt. The largest increases occur among the totally disabled: from two years before to one year after disability onset, the percent applying for benefits increases from 1.9 to 26.8 percent, and the percent receiving benefits increases from 1.3 to 48.2 percent.

The simultaneous decline in earnings and increase in disability application and receipt suggest that disability insurance may play an important role in the dynamic relationship between disability onset and earnings. Quantifying its precise role requires measuring the effect of disability application and receipt on earnings. The strategy for measuring the effect is inspired by Bound (1989), who posits that, in the absence of disability insurance, labor outcomes for accepted applicants can be no better than the outcomes for rejected applicants. If so, the effect of disability insurance on labor outcomes among accepted applicants is bounded by the observed labor outcomes of rejected applicants. He concludes that fewer than 50 percent of accepted applicants would return to sustained work had they been denied.

Extrapolating the logic of Bound, this study uses a third group - the disabled who never apply - to bound the effects of disability insurance on earnings. The analysis suggests that disability insurance accounts for little of the initial drop in earnings at the time of disability onset, but its effect may be larger as time since disability onset elapses. These conclusions are derived from a fixed-effects model that bounds the effects as well as a matching model that estimates them directly. The results are largely attributable to the fact that individuals who report total disabilities exhibit declines in earnings regardless of whether they apply for benefits.

Since Bound (1989), several studies bound the labor disincentive effects of disability insurance using the observed labor supply of rejected applicants (Bound, Burkhauser, and Nichols 2003; Chen and van der Klaauw 2008; Maestas and Yin 2008; and von Wachter, Song, and Manchester 2010). A limitation of this strategy, as Bound (1989) and Parsons (1991) have noted, is that applying for benefits may adversely affect the labor outcomes of rejected. As a result, the bound constructed from rejected applicants might understate the labor effects among accepted applicants had they never applied. This study attempts to address this limitation using 
the observed labor supply of disabled non-applicants. The matching estimates suggest that, among the sample studied, the percent of rejected applicants with positive earnings would be about 10 percentage points higher - roughly 70 percent versus 60 percent - in the absence of disability insurance.

\section{Data}

The data for the study come from a unique match of survey data to administrative data from the SSA. The survey data come from the Survey of Income and Program Participation, which are pooled across panel years 1990, 1991, 1992, 1993, and 1996. The administrative data include the Numident file, containing dates of death; the Detailed Earnings Record, reporting annual earnings from 1978 to 2004; the SSR, containing dates of SSI application and receipt; the 831 file, containing dates of SSDI application; and the Master Beneficiary Record, reporting application and receipt dates for SSDI and retirement benefits. The sample is restricted to survey data successfully matched to administrative data, which depends on whether the survey respondent reports a Social Security number and consents to the match.

Retrospective information on work-limiting disabilities is reported in topical module two of the SIPP. In this module, survey respondents first report whether they currently have a disability that limits work and, if so, the year and month they became work-limited. If worklimited, respondents then report whether they currently have a disability that prevents work and, if so, the year and month they became work-prevented. Disabled respondents are dropped from the sample if the date of disability onset is missing, if the work-prevention date precedes the work-limitation date, or if the date of disability onset occurs more than five years before the survey year. The final restriction prevents the disabled sample from being overrepresented by

the chronically disabled, because respondents are only asked about work disabilities at present, not about disabilities from which they have since recovered. The final restriction also ensures that seven years of pre-disability earnings are available for the entire disabled sample.

Finally, the sample is restricted to males whose reference ages range from 30 to 53 . For the disabled, the reference age is the age at disability onset; for the non-disabled, the reference age is the age at the time of the survey. The age range reflects that earnings are examined seven years before to seven years after disability onset, so the analysis period covers ages 23 to 60 . The sample also excludes respondents that received primary retirement benefits during the analysis period (95 respondents) or primary disability benefits before the analysis period (260 
respondents). One observation is dropped for outlying earnings. The final sample consists of 37,323 observations.

\section{Summary of disability severity, earnings, and benefit application and receipt}

\section{A. Disability Severity}

The objective of this study is to account for disability insurance in the dynamic relationship between disability onset and earnings. The relationship between disability and earnings has been the subject of recent studies using data from the Panel Study of Income Dynamics (Charles 2003; Mok, Meyer, Charles, and Achen 2008; Meyer and Mok 2008); however, no study examines this relationship using SIPP data matched to administrative earnings. Thus, the first step of the analysis is to measure the relationship between disability and earnings using SIPP-matched data.

The data are separated into three disability-severity groups: totally disabled, partially disabled, and non-disabled. Assignment to these categories is based on retrospective information on work-limiting disabilities. Totally disabled is defined as a transition from non-disabled to work-prevented from one calendar year to the next; partially disabled is defined as a one-year transition from non-disabled to work prevented, though a subsequent transition to work prevented is possible; and the non-disabled is defined as no report of a work-limiting disability. According to these definitions, 2.8 percent of the un-weighted sample is partially disabled, and 1.6 percent is totally disabled.

\section{Data summary by disability severity}

The data, summarized in Table 1, show that disability severity is associated with several demographic and economic outcomes. First, the disabled are less likely to be young, educated, white, married, and SSDI insured. Being SSDI insured requires sufficient earnings in five of the 10 years prior to the reference year and, as such, is a relevant indicator of labor force attachment. $^{4}$ Second, the disabled exhibit greater rates of death, measured by the percent dead within seven years of the reference year. Finally, the totally disabled are substantially more likely to apply for and receive disability benefits (SSDI and SSI) than the partially disabled, and

\footnotetext{
${ }^{4}$ More precisely, SSDI insured requires 20 quarters of coverage during the 40 quarters (10 years) prior to disability application. In 2010, \$1,120 in earnings is required to earn one quarter of coverage.
} 
the partially disabled more so than the non-disabled. SSI also appears more material for the totally disabled than the partially disabled and non-disabled, indicated by the rate of SSDI or SSI relative to SSDI singly.

The table also reports three figures on the nature and context of the disabling condition: whether the disability resulted from an accident, whether the person was working at the time of disability onset, and whether the disability resulted from a work-related accident. As shown, these figures do not differ substantially between the partially and totally disabled.

\section{Earnings by disability severity}

The dynamic relationship between disability onset and average earnings is illustrated in panel A of Figure 1. The figure plots average annual earnings spanning seven years before and after the reference year which, for the disabled, corresponds with the year of disability onset. The earnings estimates include zeros, though individual-year observations are excluded if the respondent is deceased.

The panel reveals three notable patterns. First, prior to disability onset, earnings of the totally disabled are lower than the earnings of the partially disabled, and earnings of the partially disabled are lower than those of the non-disabled. Second, average earnings decline precipitously at the time of disability onset among both disability groups, though the decline is greater for the totally disabled: from one year before to one year after disability onset, earnings of the totally disabled declined by 77.1 percent $(\$ 18,352)$, compared to 21.0 percent $(\$ 7,412)$ among the partially disabled. Earnings do not recover after disability onset. ${ }^{5}$

An alternative to average earnings, which measures labor supply on the intensive margin, is any positive earnings, which measures labor supply on the extensive margin. The percent of individuals with positive earnings is plotted in Panel B of Figure 1. As shown, before disability onset, the rates are similar between the partially disabled and non-disabled, but are slightly lower among the totally disabled. At the time of disability onset, the percent trends downward among the partially disabled, but declines precipitously among the totally disabled. Among the totally disabled, the estimate never drops below 25 percent and recovers slightly as time since disability onset elapses, despite the definition of total disability.

\footnotetext{
${ }^{5}$ Charles (2003) finds that earnings appear to recover among the disabled shortly after the initial decline in earnings at the time of disability onset.
} 
The raw earnings data reveal that disability onset is associated with a noticeable drop in earnings. However, disability onset is associated with demographic factors which themselves affect earnings over time. I account for observable differences between the disabled and nondisabled using a multivariate regression model, similar to the models by Jacobson, LaLonde, and Sullivan (1993); Stephens (2001); Charles (2003); and Meyer and Mok (2008). The fixedeffects model is given by

$$
y_{i t}=\alpha_{i}+\gamma_{t}+x_{i t} \beta+\sum_{s} \sum_{k} \delta_{k}^{s} A_{k i t}^{S}+\varepsilon_{i t},
$$

where $y_{i t}$ is either earnings or an indicator of any positive earnings. The coefficients $\alpha_{i}$ and $\gamma_{t}$ are individual and year fixed-effects, respectively. $x_{i t}$ is a vector of time-varying controls for age (age and age squared), education (indicators of at least a high school diploma and college degree, both interacted with age and age squared), race (exclusive indicators of being white interacted with age and age squared), and marital status (an indicator of being married two years before the reference year interacted with age and age squared). The coefficients on the timevarying covariates and the year fixed effects are identified from both the disabled and the nondisabled. ${ }^{6} A_{\text {kit }}^{s}$ is an indicator of disability severity, denoted $s$, exactly $k$ years away from the reference year. Leaving out the year prior to disability onset $(k=-1), k$ ranges from negative seven to positive seven. $\varepsilon_{i t}$ is the error term.

The estimates $\delta_{k}^{S}$ measure the association between disability onset and earnings. Because of the individual fixed effects, and because of the left-out year, the coefficients reflect the withinperson change in earnings among the disabled relative to the year prior to disability onset. The estimates of $\delta_{k}^{S}$ are reported in Panel A of Table 2. As shown, prior to disability onset, earnings remain stable among the partially disabled, but decline slightly among the totally disabled. At the time of disability onset, earnings decline precipitously among both groups, though the drop is greater among the totally disabled. The earnings of the partially disabled do not appear to recover, remaining around $\$ 9,000$ below pre-disability earnings. The earnings of the totally disabled recover slightly, increasing from negative $\$ 20,000$ two years after disability onset to negative $\$ 17,100$ seven years after onset.

\footnotetext{
${ }^{6}$ For the disabled, the analysis period is limited to seven years before and after disability onset. For the non-disabled, the analysis period may extend beyond seven years of the reference year, but is restrained to the calendar years and ages that are covered by the disabled sample.
} 
The estimates of $\delta_{k}^{S}$ for positive earnings are presented in Panel B of Table 2. The pattern of the coefficients in Panel B is substantively similar to that in Panel A: rates of positive earnings remain stable prior to onset, decline at the time of onset, and slightly recover only among the totally disabled.

\section{Benefit application and receipt by disability severity}

The data reveal that disability onset is associated with an immediate drop in earnings. However, the extent to which the drop reflects the causal effect of health on earnings remains unknown. An obvious concern, and focus of this study, is the effect of SSDI and SSI on earnings, because these programs require individuals to have earnings below a certain threshold to qualify for benefits.

The scope to which SSDI and SSI could explain the drop in earnings depends on the incidence of disability application and receipt at the time of disability onset: the greater the increase in benefit application and receipt, the greater the potential role of disability insurance in the dynamic relationship between disability onset and earnings. I therefore plot rates of disability application and receipt with respect to the date of disability onset in panels A and B of Figure 2. ${ }^{7}$ As shown, the date of disability onset coincides with sharp increases in both disability application and receipt. Among the totally disabled, disability applications increase from 5.2 percent in the year preceding disability onset to 29.1 and 26.8 percent in the year during and after disability onset, respectively. The corresponding rates for the partially disabled are 0.71, 4.9, and 7.6. The rates for both groups taper towards zero by year seven after disability onset. In regards to receipt, only 4.3 percent of the totally disabled and 0.4 percent of the partially disabled were receiving disability benefits in the year prior to disability onset. In the year immediately after onset, these rates increased to 55.1 and 8.5 percent. Both rates tend to increase as time since disability onset elapses.

The simultaneous drop in earnings and increase in disability application and receipt suggest that disability insurance might explain some of the drop in earnings at the time of onset. On one hand, the effect of disability insurance on earnings may be greater among the totally disabled than the partially disabled, because the former are more likely to apply for and receive benefits. On the other hand, the effect may be greater among the partially disabled who,

\footnotetext{
${ }^{7}$ The application rate includes initial applications, reconsiderations, and appeals for both SSDI and SSI. The benefit receipt rate refers to the rate of both SSDI and SSI.
} 
ostensibly, are in better health and thus forgo more earnings to apply for and receive benefits. Determining the precise role of disability insurance in the relationship between disability and earnings, therefore, requires knowing the causal effect of disability insurance on earnings.

\section{B. Benefit application and receipt}

The causal effect of disability insurance on earnings is simple to define conceptually, though difficult to measure empirically. Conceptually, the effect of applying for benefits is measured by the difference in earnings in the applicant and non-applicant states. Likewise, the effect of receiving disability benefits is measured by the difference in earnings in the beneficiary and non-beneficiary states. The empirical difficulty arises because earnings are only observed in one state for each individual. Thus, estimating the effect for applicants and beneficiaries is tantamount to estimating counterfactual earnings had applicants not applied for - or had beneficiaries not received - benefits.

In a seminal paper, Bound (1989) estimates this type of counterfactual for the labor force participation of SSDI beneficiaries. His empirical strategy presumes that, because of the disability screening process, rejected applicants are healthier than accepted applicants. If so, and if the supply of and demand for labor supply are positively related to one's health, then the disability screening process ensures that the labor market prospects for rejected applicants are better than those for accepted applicants. Therefore, the counterfactual labor supply of accepted applicants is bounded by the observed labor supply of rejected applicants.

Following Bound, I first consider earnings of rejected applicants as a bound on earnings of accepted applicants. However, as Bound and others note, this strategy does not account for the possibility that the application process itself may adversely affects earnings. I therefore examine the earnings of a third group: the disabled who do not apply for benefits. Shown by Lahiri, Song, and Wixon (2008), the likelihood of applying for benefits is negatively related to earnings in the non-applicant state. Thus, earnings of non-applicants likely bound the potential earnings of rejected applicants, as well as accepted applicants, had they never applied. 


\section{Data summary by benefit application and receipt}

The disabled sample is separated into three groups: accepted applicants, rejected applicants, and non-applicants. ${ }^{8}$ Summary statistics, presented in Table 3, reveal several broad patterns across groups. First, compared to non-applicants, applicants are less likely to be young, educated, white, and married. Second, accepted applicants are more likely to be totally disabled than rejected applicants, and rejected applicants more so than non-applicants. Third, compared to rejected applicants and non-applicants, accepted applicants are less likely to be disabled from an accident and are significantly more likely to die by year seven after disability onset. Finally, compared to rejected applicants and non-applicants, accepted applicants are less likely to be disabled from back pain, stiffness, or deformity, and more likely to be disabled from cancer, heart trouble, chronic kidney problems, or stroke.

\section{Earnings by benefit application and receipt}

Following Bound and others, average earnings of the recently disabled are plotted separately by application and receipt status. These trends are shown in Panel A of Figure 3. As shown, prior to the reference year, earnings of rejected applicants were lower than the earnings of accepted applicants, and those of accepted applicants were lower than those of nonapplicants. ${ }^{9}$ At the time of disability onset, earnings of all three groups decreased, but the declines are noticeably greater among the two applicant groups. After the initial drop in earnings, earnings of accepted applicants decrease, whereas earnings of rejected and nonapplicants rise.

The percent with positive earnings is plotted in Panel B of Figure 3. As shown, before disability onset, the percent is similar across all three groups. At the time of onset, the percent declines for all three groups, but declines substantially more among accepted applicants. After disability onset, the percent trends downward among accepted applicants and upward among rejected applicants.

\footnotetext{
${ }^{8}$ Accepted applicants are defined as applying for and receiving benefits during the analysis period; rejected applicants are defined as applying for but never receiving benefits during the analysis period; non-applicants are defined as never applying for or receiving benefits during the analysis period.

${ }^{9}$ Lahiri, Song, and Wixon (2008) find that, before applying, the earnings of rejected applicants are lower than the earnings of accepted applicants.
} 
I first consider the earnings of rejected applicants as a bound on the earnings of accepted applicants had they been rejected. The data reveal that, three years following disability onset, when most disability claims had been filed, 59.6 percent of rejected applicants have positive earnings. Thus, had the accepted been rejected, at most, 60 percent of them would have positive earnings. ${ }^{10}$ This estimate is similar in magnitude to von Wachter, Song, and Manchester (2010), who find that about 50 to 60 percent of young, rejected applicants have positive earnings two years after rejection.

Mentioned above, a concern with a bound constructed from rejected applicants is that the application process itself may adversely affect earnings. I therefore consider the earnings of non-applicants as a bound on the earnings of rejected and accepted applicants had they never applied. Unfortunately, from Panels A and B of Figure 3, the bound constructed from nonapplicants is uninformative: compared to applicants, the earnings of non-applicants are substantially higher both before and after disability onset. In the next section, an attempt is made to obtain more informative estimates of the effects of disability insurance on earnings.

\section{The effect of benefit application and receipt on earnings}

Two strategies are used to obtain tighter estimates of the effects of disability insurance on earnings. The first strategy is an individual fixed-effects model, similar to (1), that arguably bounds the earnings effect. The model generates tighter estimates by controlling for average earnings between individuals and for the effects of time-varying covariates. The second strategy is a matching model that systemically pairs applicants to non-applicants - the difference in earnings between the pair is taken as the effect of disability insurance on earnings. The difference between the two models is that the first bounds the earnings effect, whereas the second estimates it directly.

\section{A. Fixed-Effects Model}

The fixed-effects model is similar to (1), but here, $s$ indexes the three states of application and receipt: accepted, rejected, and non-applicants. The left-out group is the non-disabled. As before, the model contains age; age squared; and the interactions of age and age squared with race, education, and marital status. Average differences in earnings across individuals are

\footnotetext{
${ }^{10}$ This estimate cannot be directly compared to Bound's (1989) because, in his study, the analysis sample is limited to males over the age of 45 .
} 
absorbed by the individual fixed effects, so $\delta_{k}^{s}$ measures the within-person association between applicant status and earnings relative to the year prior to disability onset.

The values of $\delta_{k}^{S}$ are estimated simultaneously for accepted, rejected, and non-applicants; but for ease of exposition, the estimates are presented separately in the first columns of Tables 4 and 5 - Table 4 contains the estimates for accepted applicants, denoted $\delta_{k}^{A}$; Table 5 contains the estimates for rejected applicants, denoted $\delta_{k}^{R}$. According to the estimates for earnings, reported in Panel A, the drop in earnings at the time of disability onset is comparable between rejected and accepted applicants. However, as time since disability onset elapses, earnings of rejected applicants recover slightly, whereas earnings of accepted applicants decline. By year seven after disability onset, the decline in earnings among accepted applicants is twice as large as the decline among rejected applicants: $\$ 22,300$ versus $\$ 11,100$.

The estimates for the likelihood of any positive earnings are reported in Panel B. At the time of disability onset, the likelihood declines more among accepted than rejected applicants. As before, as time since disability elapses, the likelihood increases among rejected applicants and decreases among accepted applicants. By year seven after disability onset, the likelihood is - 12 percentage points among rejected applicants and - 59.3 percentage points among accepted applicants.

The estimates of $\delta_{k}^{A}$ and $\delta_{k}^{R}$ simply measure the association between application status and earnings, so conceptually, they themselves serve as upper bounds of the earnings effect of disability application and receipt. However, the estimates also reflect all other mechanisms that correlate health with earnings, including the causal effect of health on earnings, the causal effect of earnings on health, and the bias from individuals justifying low earnings with poor health. Netting out these other mechanisms, if possible, yields the effect of disability insurance on earnings: $\hat{\delta}_{k}^{A}-E\left[\delta_{k}^{N} \mid A=1\right]$ for accepted applicants and $\hat{\delta}_{k}^{R}-E\left[\delta_{k}^{N} \mid R=1\right]$ for rejected applicants, where $\delta_{k}^{N}$ is the drop in earnings when not applying. The empirical difficulty arises because $E\left[\delta_{k}^{N} \mid A=1\right]$ and $E\left[\delta_{k}^{N} \mid R=1\right]$ are unobserved.

One strategy is to bound the differences $\hat{\delta}_{k}^{A}-E\left[\delta_{k}^{N} \mid A=1\right]$ and $\hat{\delta}_{k}^{R}-E\left[\delta_{k}^{N} \mid R=1\right]$ using the observed change in earnings among non-applicants: $E\left[\delta_{k}^{N} \mid N=1\right]$. The bounding estimate requires that the observed drop in earnings among non-applicants would be smaller than the counterfactual drop in earnings among applicants in the non-applicant state: $E\left[\delta_{k}^{N} \mid N=1\right]>$ $E\left[\delta_{k}^{N} \mid A=1\right]$ and $E\left[\delta_{k}^{N} \mid N=1\right]>E\left[\delta_{k}^{N} \mid R=1\right]$. This assumption seems reasonable 
considering that applicants are less educated, they report more severe disabilities, and they exhibit greater rates of death. If the assumption is true, then in absolute value, $\hat{\delta}_{k}^{A}-$ $E\left[\delta_{k}^{N} \mid A=1\right]$ is bounded by $\hat{\delta}_{k}^{A}-\hat{\delta}_{k}^{N}$, and $\hat{\delta}_{k}^{R}-E\left[\delta_{k}^{R} \mid A=1\right]$ is bounded by $\hat{\delta}_{k}^{R}-\hat{\delta}_{k}^{N}$.

The bounding estimates $\hat{\delta}_{k}^{A}-\hat{\delta}_{k}^{N}$ and $\hat{\delta}_{k}^{R}-\hat{\delta}_{k}^{N}$ are reported in Tables 4 and 5, respectively, under the heading “Diff-in-Diffs.” (Estimates of $\delta_{k}^{N}$ are not reported separately.) As shown, the new bounds are smaller in absolute value than the baseline estimates, particularly at the time of disability onset. The smaller bounds reflect that, at the time of disability onset, the earnings decline significantly among both applicants and non-applicants, illustrated in Figure 3. The bound remains relatively stable among rejected applicants, but becomes larger among accepted applicants as time since disability onset elapses, reflecting both an increase in earnings among non-applicants (smaller $\hat{\delta}_{k}^{N}$ in absolute value) and a decrease in earnings accepted applicants (larger $\hat{\delta}_{k}^{A}$ in absolute value). By year seven after onset, the bound among accepted applicants reaches $\$ 17,700$.

\section{B. Matching Estimates}

The second strategy is a matching model. ${ }^{11}$ Conceptualized above, the effect of disability insurance on earnings is measured as the difference in earnings in the applicant and nonapplicant states. Thus, in a given period, the effect of disability insurance on earnings among accepted applicants is measured by $Y(N=1 \mid A=1)-Y(A=1 \mid A=1)$, denoted $\gamma^{A}$, where $Y(N=1 \mid A=1)$ is counterfactual earnings in the non-applicant state conditional on being accepted. Similarly, the effect among rejected applicants is given by $Y(N=1 \mid R=1)-Y(R=$ $1 \mid R=1)$, denoted $\gamma^{R}$, where $Y(N=1 \mid R=1)$ is counterfactual earnings in the non-applicant state conditional on being rejected.

Unfortunately, $\gamma^{A}$ and $\gamma^{R}$ cannot be estimated because $Y(N=1 \mid A=1)$ and $Y(N=1 \mid R=1)$ are unobserved. However, they can be estimated using a matching model based on three identifying assumptions. The first assumption is that, conditional on a set of factors $\mathrm{Z}$, earnings in the non-applicant state are independent of application or receipt status: $Y(N=1 \mid A=1, Z)=Y(N=1 \mid R=1, Z)=Y(N=1 \mid N=1, Z)=Y(N=1 \mid Z)$. The second assumption is that, for each accepted and rejected applicant, there is an analogue nonapplicant: $\operatorname{Pr}(N=1 \mid Z)>0$. The third assumption is that applying for or receiving disability

11 The use of matching models in evaluating labor market programs is surveyed in Heckman, LaLonde and Smith (1999). 
benefits does not affect the conditioning factors Z. Based on these assumptions, the effect of disability insurance on earnings can be estimated by pairing applicants to non-applicants based on $\mathrm{Z}$ : the average of earnings difference between pairs is the estimated effect of disability insurance on earnings.

Applicants are paired with non-applicants using a matching program developed by Abadie, Drukker, Herr, and Imbens (2004). Applicants are matched to only one non-applicant using nearest neighbor matching with replacement. Factors in $\mathrm{Z}$ include education (exclusive indicators of at least a high school diploma and a college degree); age at reference year; calendar year of the reference year; marital status two years prior to the reference year; disability insurance status at the time of disability onset; race (an indicator of being white); mortality (an indicator of death seven years after disability onset); state of residence (indicators of state of residence); average income over six years, spanning from seven to two years prior to the reference year; and type of disabling condition. ${ }^{12}$ Applicants are also exactly matched to nonapplicants based on disability severity.

The matching estimates for accepted applicants are reported in the final columns of Tables 4. As shown, disability insurance explains less than a third of the drop in earnings at the time of disability onset: about $\$ 5,000$ of the $\$ 16,900$ drop in earnings in the year after onset is attributable to disability insurance. However, disability insurance explains more as time since disability onset elapses. By year seven after onset, $\$ 19,000$ of the $\$ 22,300$ drop in earnings is attributable to disability insurance. A similar pattern emerges from the estimates for positive earnings, reported in Panel B of Table 4.

Matching estimates for rejected applicants are reported in the final columns of Table 5. Similar to accepted applicants, the effect of disability insurance on earnings is smallest at the time of disability onset and increases as time since onset elapses. Comparing the estimates in Table 5 to those for accepted applicants in Table 4, disability insurance generally affects earnings more among accepted applicants, but explains a greater fraction of the overall decline in earnings among rejected applicants.

\section{Counterfactual Earnings Trends of the Disabled in the Absence of Disability Insurance}

\footnotetext{
${ }^{12}$ When matching applicants to non-applicants, the weight assigned to each covariate is inversely related to its variance, a technique that accounts for the different scales of the covariates.
} 
The role of disability insurance in the dynamic relationship between disability onset and earnings can be illustrated by plotting the observed relationship, illustrated in Figure 1, alongside the counterfactual relationship in the absence of disability insurance. The counterfactual can now be constructed using the estimated effect of disability insurance on earnings. In particular, if observed earnings in period $\mathrm{k}$ for disability severity group $\mathrm{s}$ is denoted $\bar{y}_{k}^{S}$, then counterfactual earnings in the absence of disability insurance is $\bar{y}_{k}^{S}-p_{k}^{S A} \hat{\gamma}_{k}^{A}-$ $p_{k}^{S R} \hat{\gamma}_{k}^{R}$, where $p_{k}^{S A}$ is the percent of individuals that are accepted, $p_{k}^{S R}$ is the percent of individuals that are rejected, and $\hat{\gamma}_{k}^{A}$ and $\hat{\gamma}_{k}^{R}$ are the matching estimates of effect of disability insurance on earnings. $^{13}$

The observed and counterfactual trends are illustrated in Figure $\mathbf{4}$ for the partially disabled and in Figure 5 for the totally disabled. Within each figure, the trends in earnings are illustrated in Panel A, and the trends in positive earnings are illustrated in Panel B. In general, the illustrations indicate that disability insurance plays a minor role at the time of disability onset, but its role increases as time since disability onset elapses. For the totally disabled, the difference between counterfactual and actual earnings in the year after onset is $\$ 4,500$, and the difference in the percent with positive earnings is 6.6 points. By year seven following onset, these differences are $\$ 14,100$ and 34.1 points, respectively.

\section{Additional Considerations}

\section{A. Disability Severity}

The matching estimates in Table 4 and 5 measure the effect of disability insurance on earnings among all accepted and rejected applicants regardless of disability severity. An obvious question is whether the effect of disability insurance varies by disability severity. The answer can be surmised from Figures 6 and 7, which plot earnings by application and receipt status and disability severity. Earnings of the partially disabled are plotted in Figure 6; earnings of the totally disabled are plotted in Figure 7. Among the partially disabled, only the earnings of applicants decline at the time of disability onset. In contrast, earnings of the totally disabled decline regardless of disability application. Taken together, the figures suggest potentially large

\footnotetext{
13 The calculation of counterfactual earnings assumes that the effect of disability insurance on earnings is the same among the partially and totally disabled. The possibility that the effect varies by disability severity is examined in the next section.
} 
effects of disability insurance among the partially disabled, but negligible effects among the totally disabled, particularly at the time of disability onset.

\section{B. Back and Spine Problems}

The SSA uses a single criterion to determine medical eligibility: the beneficiary must be unable to engage in substantial, gainful activity. However, evaluating musculoskeletal conditions and mental illness requires more subjectivity than conditions like stroke and cancer. A policy concern is whether greater subjectivity leads to higher rates of false-positive awards and, as a result, to larger adverse effects on labor supply. To address this concern, I repeat the entire analysis for males who report that a back or spine problem limits work. The focus on this condition is important: 31.2 percent of all disabled worker awards in 2009 are attributable to musculoskeletal and connective tissue conditions (SSA 2009). Moreover, problems with the back and spine are the most common disabilities reported in the SIPP. According to Table 3, these disabilities are less common among accepted applicants relative to rejected applicants and non-applicants.

The observed and counterfactual trends in earnings are reported in Figures 8 and 9. Figure 8 corresponds with the partially disabled; Figure 9 corresponds with the totally disabled. As before, there is little difference between observed and counterfactual earnings at the time of disability onset, suggesting that the drop in earnings when a back or spine problem manifests is not driven by disability insurance. With time, however, counterfactual earnings increase and observed earnings remain stagnant, again suggesting that the effect of disability insurance on earnings may increase with time.

\section{Earnings Uncertainty}

Studies documenting the dynamic relationship between disability onset and earnings focus on changes in earnings on average. However, another source of welfare loss that may be associated with disability onset is increased earnings uncertainty (Currie and Madrian 1999). The increase in uncertainty may arise from productivity risk - for example, increased bed days and from employment risk - for example, increased fluctuations in labor demand from disabled 
workers. ${ }^{14}$ The effect of health on earnings uncertainty is important because, as earnings uncertainty increases, so too does the incentive to apply for disability benefits. ${ }^{15}$

Using the date of disability onset, combined with the data on longitudinal earnings data, I examine whether disability onset is associated with increased earnings uncertainty. Two factors complicate the analysis. First, shown above, many of the disabled apply for and receive disability benefits at the time of disability onset, so their earnings will not reflect the degree of uncertainty had they remained in the labor market. For this reason, the disabled sample is limited to those who do not apply for benefits. Second, earnings of the disabled are often bounded at zero, so the standard measure of variance would be lower than if earnings were not bounded. Therefore, the effect of disability onset on the variance of earnings is estimated using interval regression, which models earnings bounded at zero.

Latent earnings are modeled as:

$$
N\left(\theta_{0}+\theta_{1} x_{i t}+\theta_{1} D_{i t}+\theta_{2} P_{i t}+\theta_{3} D_{i t} P_{i t}, \eta_{0}+\eta_{1} D_{i t}+\eta_{2} P_{i t}+\eta_{3} D_{i t} P_{i t}\right)
$$

where $D_{i t}$ is an indicator of disability status, $P_{i t}$ is an indicator of post-reference year, and $D_{i t} P_{i t}$ is an indicator of post-disability onset among the disabled. The vector $x_{i t}$ is a set of observable characteristics that includes age, age squared, race (white), education (high school diploma and college degree), and marital status. As shown, the variance of latent earnings depends on both disability status and disability status after the reference year. The coefficient $\eta_{3}$ measures the degree to which disability onset affects earnings variance.

The interval regression estimates are presented in Table 6. As shown, disability onset is associated with a $\$ 14,700$ decline in average earnings (Panel A), but is not associated with a significant increase in earnings variance (Panel B).

\section{Discussion and Conclusion}

Several recent studies examine the dynamic relationship between disability onset and income. This work is motivated by the fact that the optimal level of disability insurance depends, in part, on the causal effect of health on earnings. However, measuring the causal

\footnotetext{
${ }^{14} \mathrm{~A}$ framework for distinguishing between productivity risk and employment risk is developed by Low, Meghir, and Pistaferri (2010).

${ }^{15}$ Kreider (1998) calculates that applications to SSDI are 15 percent higher than they would be in the absence of earnings risk prior to application. However, the study does not take into account the degree to which disability onset affects earnings uncertainty.
} 
effect of health on earnings is complicated by the fact that disability insurance itself may affect earnings, particularly at the time of a health shock. Thus, to determine the optimal level of disability insurance, it is necessary to account for the role of insurance in the dynamic relationship between disability onset and earnings.

The preliminary results from this study suggest that disability insurance may go a long way in explaining the relationship between disability and earnings: at the time of onset, earnings decrease and disability application and receipt increase. However, further analysis reveals that the recently disabled exhibit declines in earnings regardless of disability application, suggesting that the role of disability insurance in the initial drop in earnings is minor. The effect of disability insurance on earnings is potentially larger as time since disability onset elapses, because while earnings of accepted applicants decrease, earnings of non-applicants recover.

What do these findings imply for policy? An important policy question is whether SSDI or SSI beneficiaries could otherwise work. This study suggests that, had the accepted never applied, their capacity for work would be initially low, but may improve with time. Thus, to discourage SSDI and SSI applications and encourage long-run work, the initial drop in earnings could be insured with immediate, though temporary disability benefits. The SSDI program, in contrast, targets long-term disabilities with benefits available five months after onset. Because the counterfactual in this study is whereby the beneficiary never applies, the results do not imply that accepted applicants could otherwise work several years after receiving benefits. Thus, the results neither support nor disparage the use of continuing disability reviews, where the case of a disabled worker beneficiary is re-evaluated after years of receiving benefits. 


\section{References}

Abadi, Alberto, David Drukker, Jane Leber Herr, and Guido Imbens. 2004. “Implementing Matching Estimators for Average Treatment Effects in Stata.” Stata Journal 4(3): 290311.

Autor, David, and Mark Duggan. 2003. “The Rise in the Disability Rolls and the Decline in Unemployment.” Quarterly Journal of Economics 118(1): 157-206.

Black, Dan, Kermit Daniel, and Seth Sanders. 2002. “The Impact of Economic Conditions on Participation in Disability Programs: Evidence from the Coal Boom and Bust.” American Economic Review 92(1): 27-50.

Borsch-Supan, Axel. 2000. “Incentive Effects of Social Security on Labor Force Participation: Evidence in Germany and Across Europe.” Journal of Public Economics 78(1-2): 25-49.

Bound, John. 1989. “The Health and Earnings of Rejected Disability Insurance Applicants.” American Economic Review 79(3): 482-503.

Bound, John. 1991. “Self-Reported versus Objective Measures of Health in Retirement Models.” Journal of Human Resources 26(1): 106-138.

Bound, John, Richard Burkhauser, and Austin Nichols. 2003. “Tracking the Household Income of SSDI and SSI Applicants.” In Worker Well-being and Public Policy: Research in Labor Economics, ed. Solomon Polachek, 113-158. Oxford: Elsevier JAI Press.

Charles, Kerwin K. 2003. The Longitudinal Structure of Earnings Losses among Work-Limited Disabled Workers. Journal of Human Resources 38(3): 618-646.

Chen, Susan, and Wilbert Van der Klaauw. 2007. "The Work Disincentive Effects of the Disability Insurance Program in the 1990s.” Journal of Econometrics 142(2): 757-84. 
Currie, Janet and Brigitte C. Madrian. 1999. "Health, Health Insurance and the Labor Market.” In Hanbook of Labor Economics, Volume 3, eds. O. Ashenfelter and D. Card, 3309-3416. Elsevier Science.

Duggan, Mark, Robert Rosenheck, and Perry Singleton. 2010. "Federal Policy and the Rise in Disability Enrollment: Evidence for the VA’s Disability Compensation Program.” Journal of Law and Economics 53(2): 379-398.

Duggan, Mark, Perry Singleton, and Jae Song. 2007. “Aching to Retire? The Rise in the Normal Retirement Age and its Impact on the Social Security Rolls.” Journal of Public Economics 91(7-8): 1327-50.

Gruber, Jonathan. 2000. "Disability Insurance Benefits and Labor Supply." Journal of Political Economy 108(6): 1162-83.

Jacobson, Louis S., Robert J. LaLonde, and Daniel G. Sullivan. 1993. “Earnings Losses of Displaced Workers.” American Economic Review 83(4): 685-709.

Heckman, James, Robert LaLonde, and Jeffrey Smith. 1999. "The Economics and Econometrics of Active Labor Market Programs.” In Handbook of Labor Economics Volume 3A, eds. O. Ashenfelter and D. Card, 1865-2097. Amsterdam: North Holland.

Kreider, Brent. 1998. "Workers' Applications to Social Insurance Programs when Earnings and Eligibility are Uncertain.” Journal of Labor Economics 16(4): 848-877.

Lahiri, Kajal, Jae Song, and Bernard Wixon. 2008. “A Model of Social Security Disability Insurance using Matched SIPP/Administrative Data.” Journal of Econometrics 145(1-2): $4-20$. 
Low, Hamish, Costas Meghir, and Luigi Pistaferri. 2010. "Wave Risk and Employment Risk over the Life Cycle.” American Economic Review 100 (September 2010): 1432-1467.

Maestas, Nicole and Na Yin. 2008. "Labor Supply Effects of the Interaction between the Social Security Disability and Retirement Programs at Full Retirement Age.” http://www.mrrc.isr.umich.edu/publications/papers/pdf/wp194.pdf.

Meyer, Bruce D. and Wallace K. Mok. 2008. "Disability, Earnings, Income and Consumption.” The Harris School of Public Policy Studies Working Paper \#06.10.

Mok, Wallace K. C., Bruce D. Meyer, Kerwin Kofi Charles and Alexandra C. Achen. 2008. “A Note on 'The Longitudinal Structure of Earnings Losses among Work-Limited Disabled Workers.” Journal of Human Resources 43(3): 721-728.

Parsons, Donald. 1980. "The Decline in Male Labor Force Participation." Journal of Political Economy 88(1): 117-34.

Parsons, Donald. 1991. “The Health and Earnings of Rejected Disability Insurance Applicants: Comment.” American Economic Review 81(5): 1419-1426.

Social Security Administration. 2009. Annual Statistical Report on the Social Security Disabiltiy Insurance Program, 2009.

Stephens, Mel. 2001. “The Long Run Consumption Effects of Earnings Shocks.” Review of Economics and Statistics 83(1): 28-36.

von Wachter, Till, Jae Song, and Joyce Manchester. 2010. “Trends in Employment and Earnings of Allowed and Rejected Applicants to the Social Security Disability Insurance Program.” Forthcoming in the American Economic Review. 


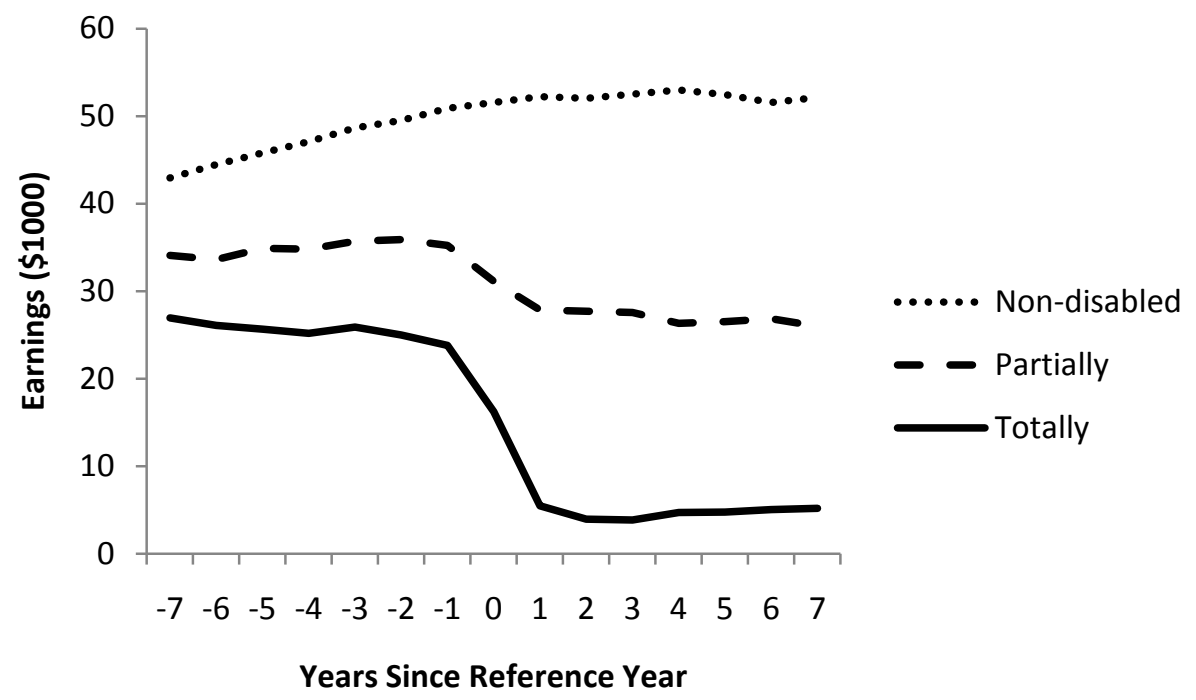

Panel A: Average Earnings

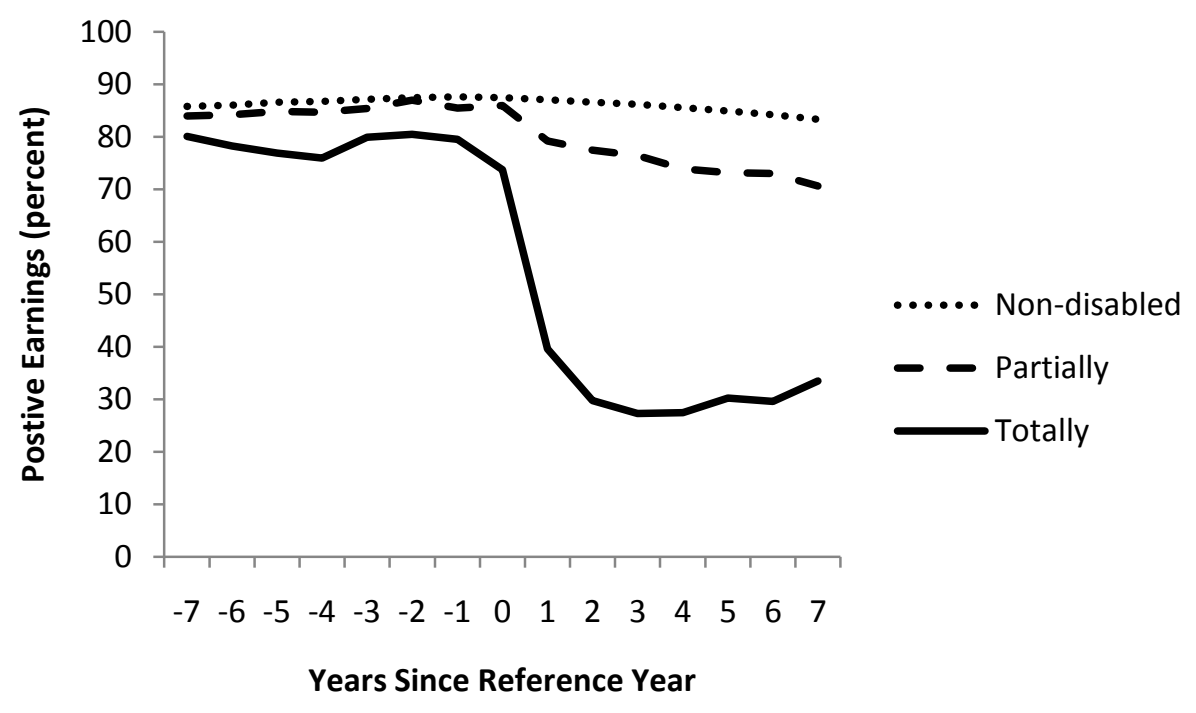

Panel B: Positive Earnings

Figure 1: Earnings by Disability Severity

Reference year zero refers to the date of disability onset for the partially and totally disabled. 


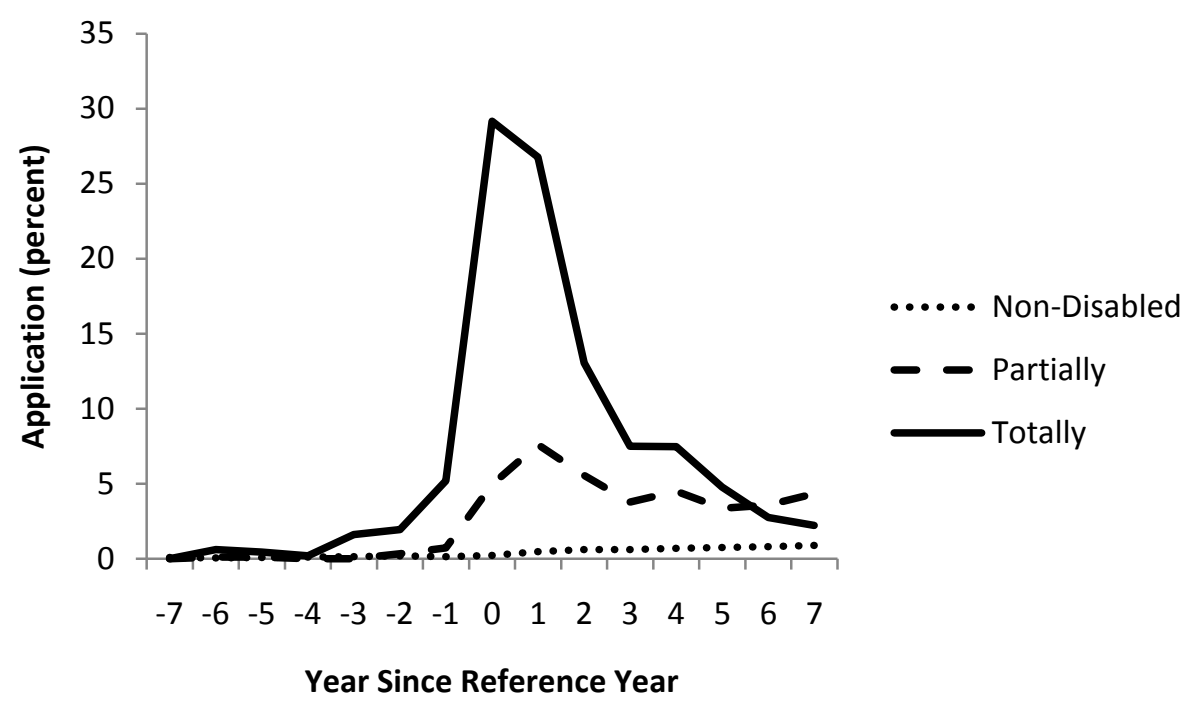

Panel A: Disability Applications

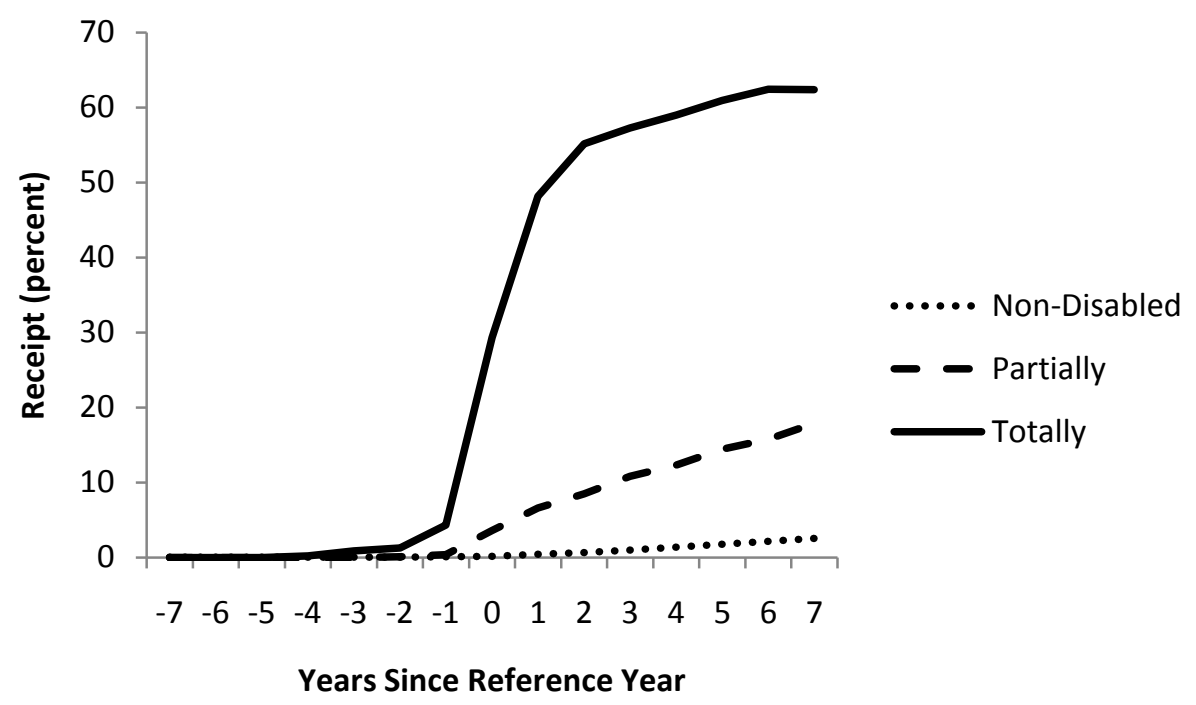

Panel B: Disability Receipt

Figure 2: Disability Application and Receipt by Disability Severity Reference year zero refers to the date of disability onset for the partially and totally disabled. 

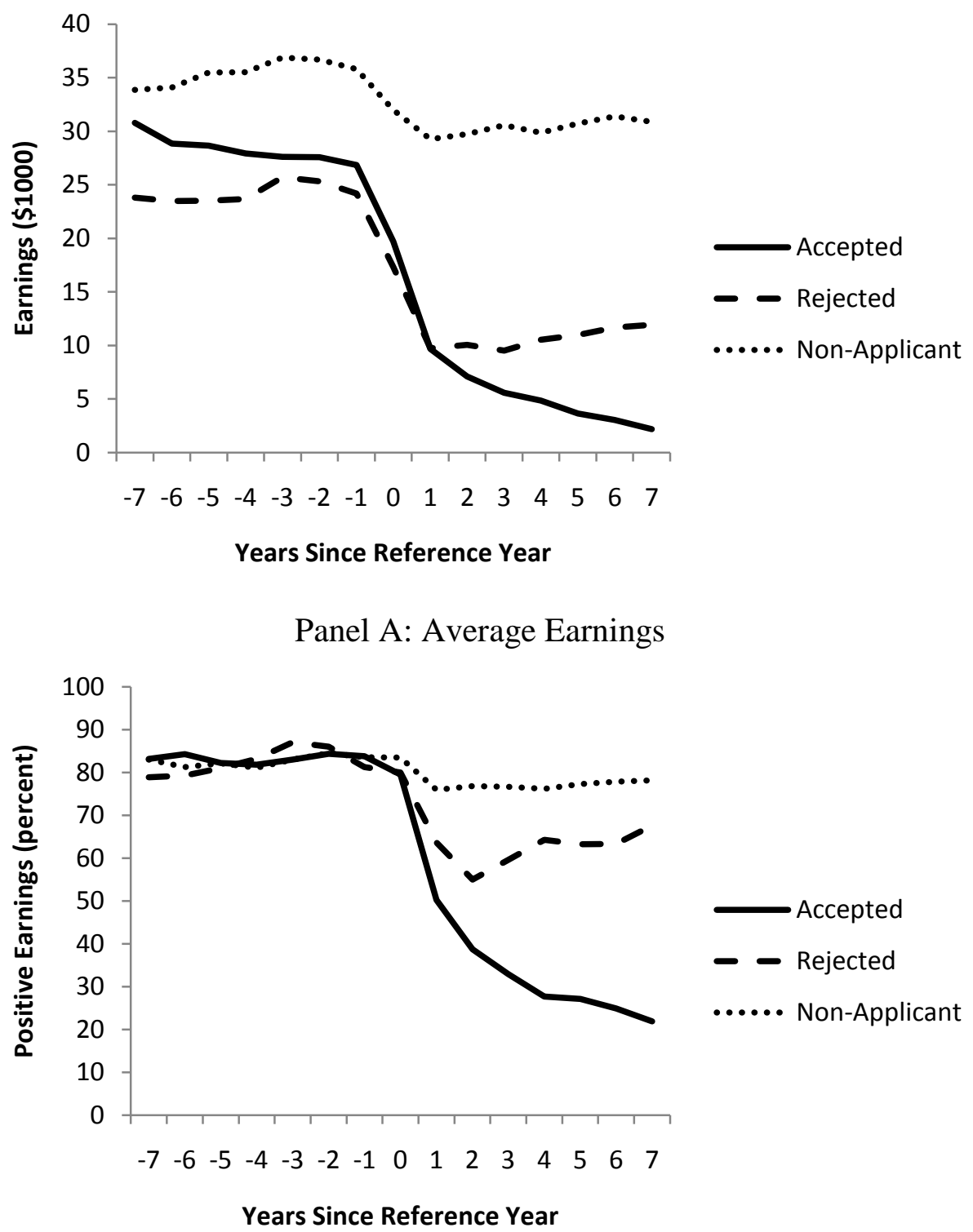

Panel B: Positive Earnings

Figure 3: Earnings by Disability Application and Receipt Status 

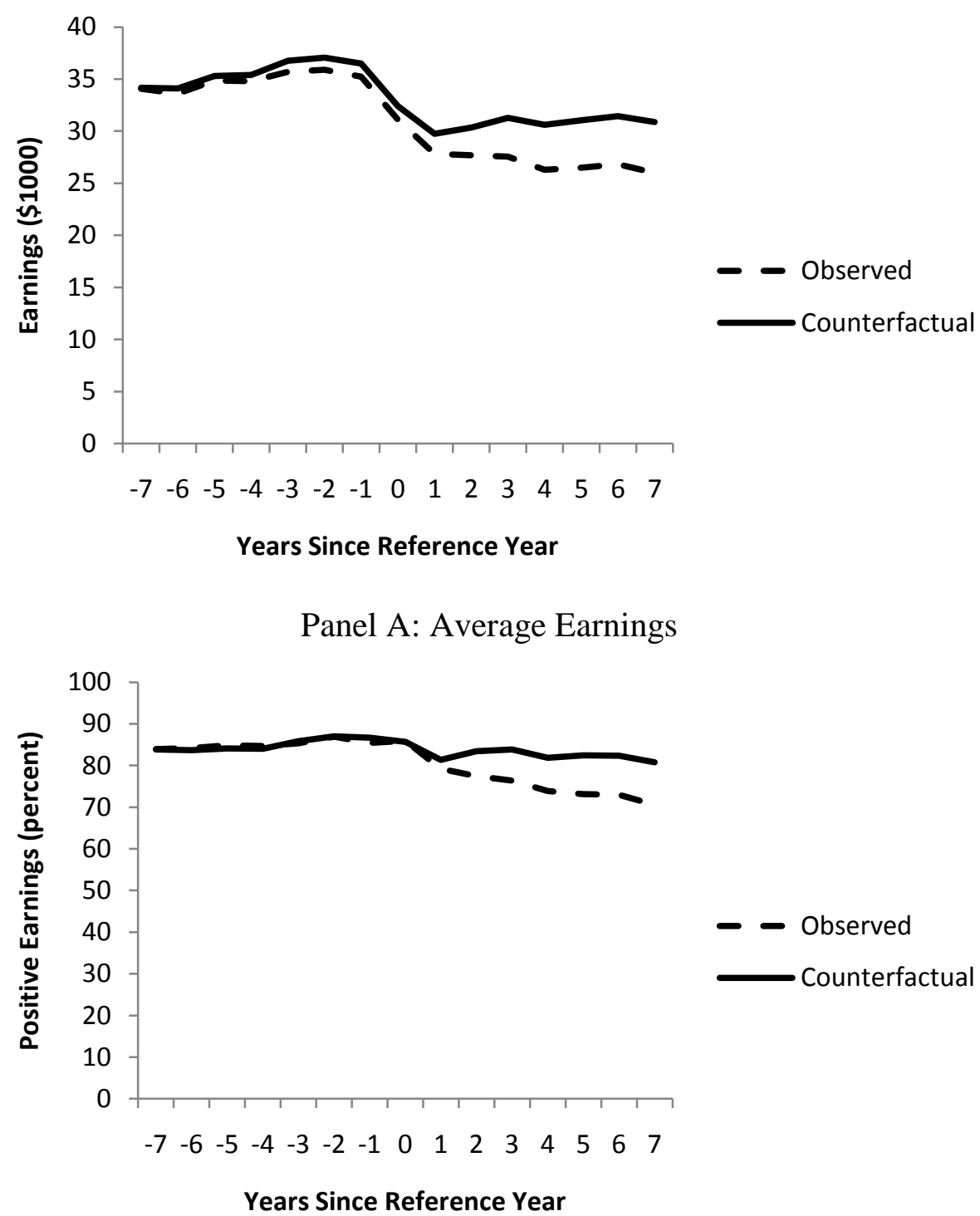

Panel B: Positive Earnings

Figure 4: Observed and Counterfactual Earnings of the Partially Disabled Counterfactual represents the upper bound of earnings of the partially disabled had none applied for disability benefits. 

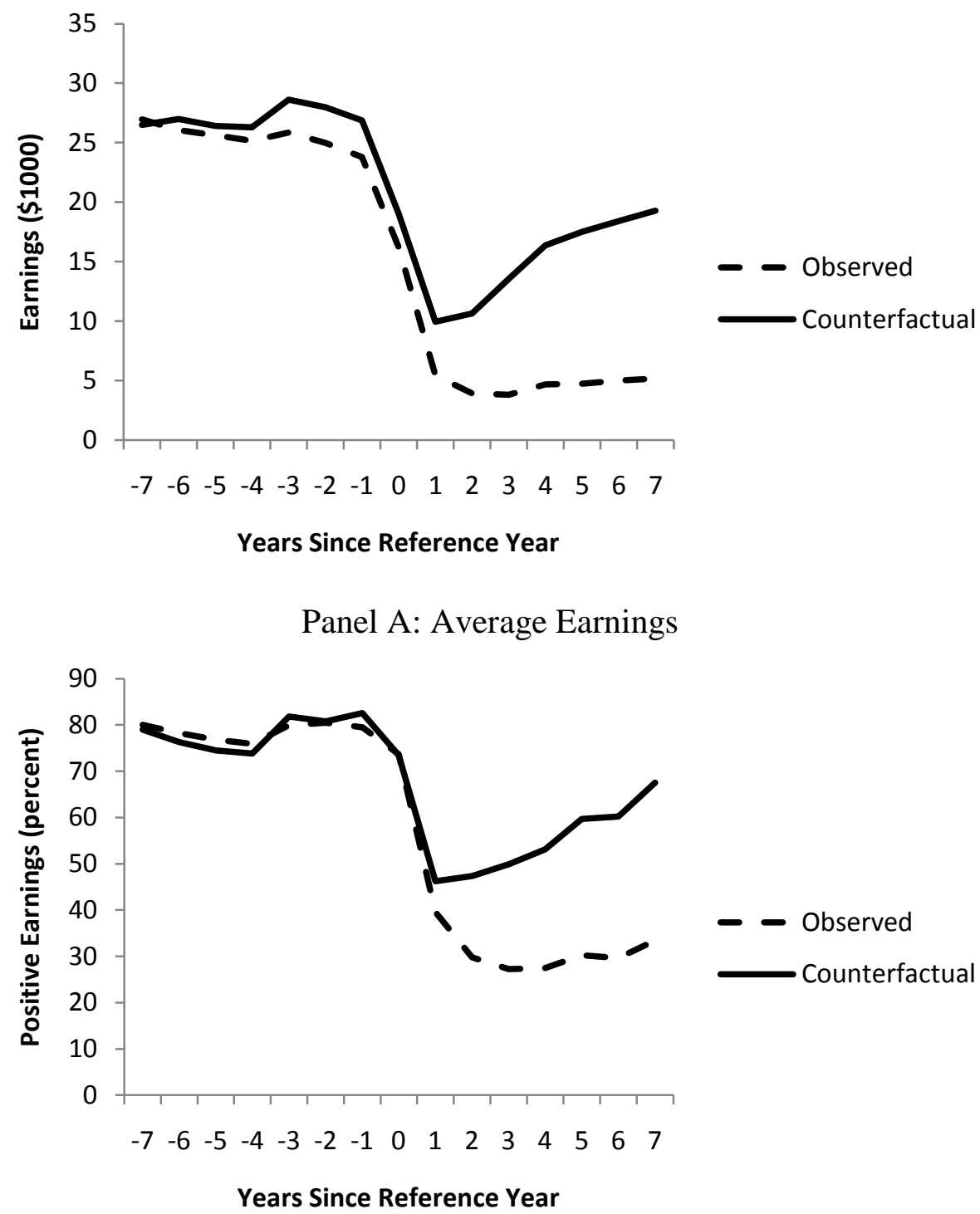

Panel B: Positive Earnings

Figure 5: Observed and Counterfactual Earnings of the Totally Disabled Counterfactual represents the upper bound of earnings of the totally disabled had none applied for disability benefits. 


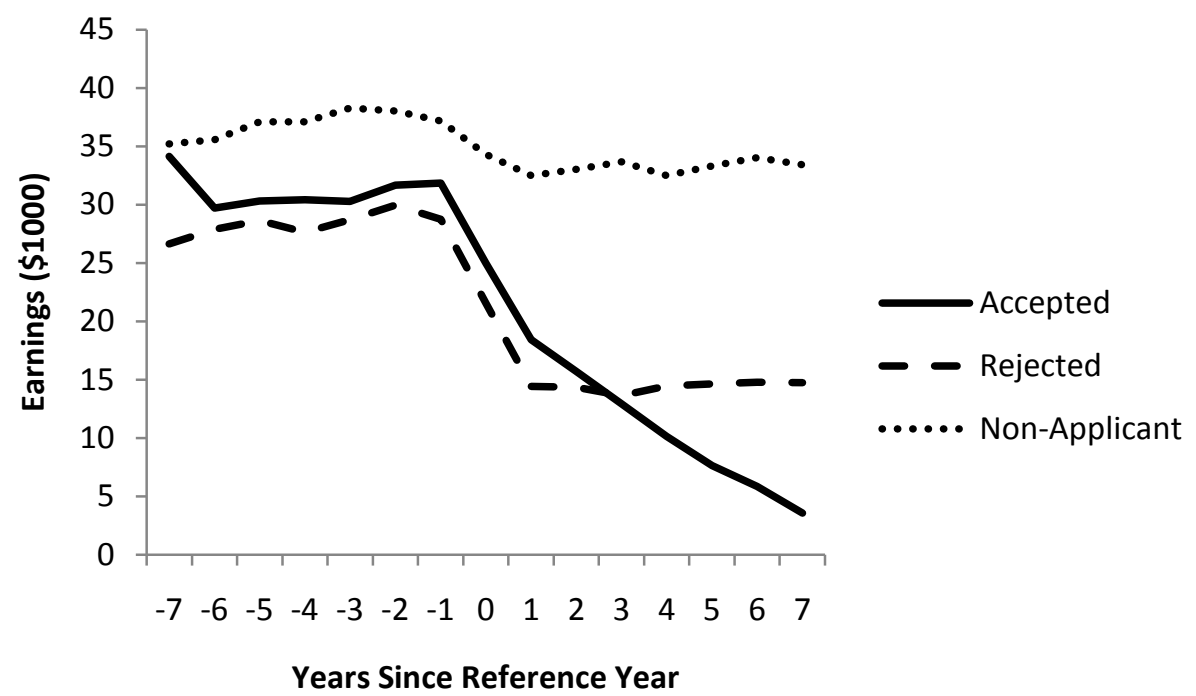

Panel A: Average Earnings

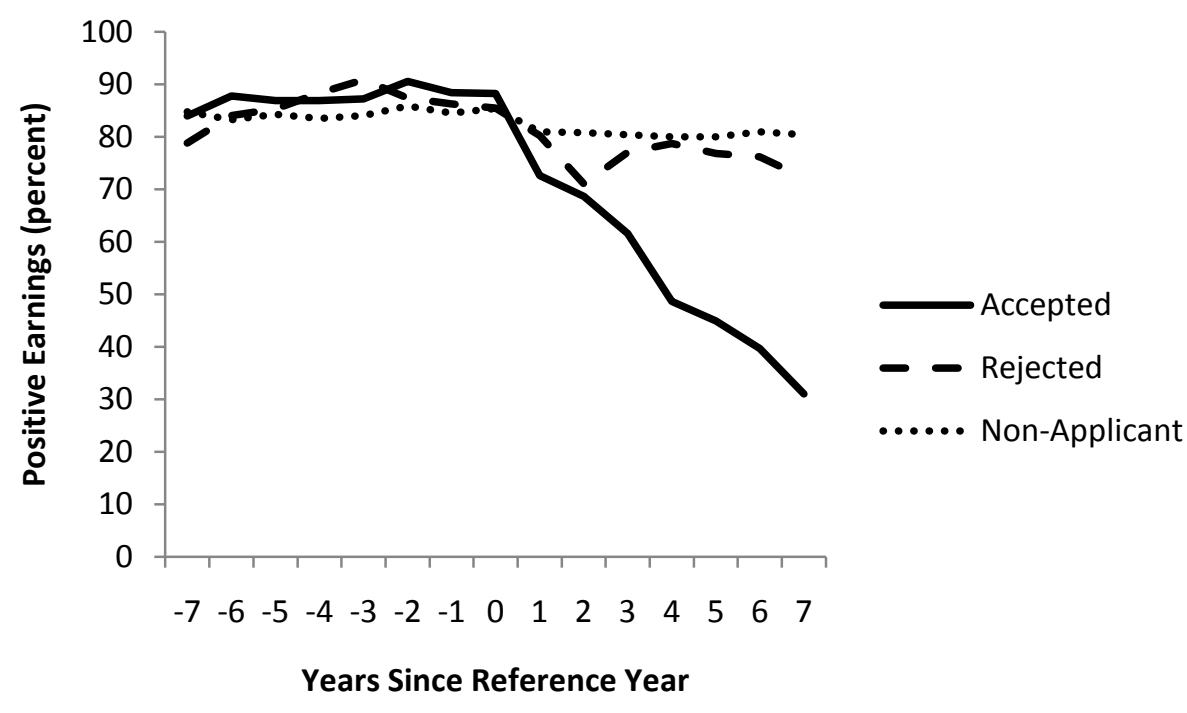

Panel B: Positive Earnings

Figure 6: Earnings by Disability Application and Receipt Status: Partially Disabled 


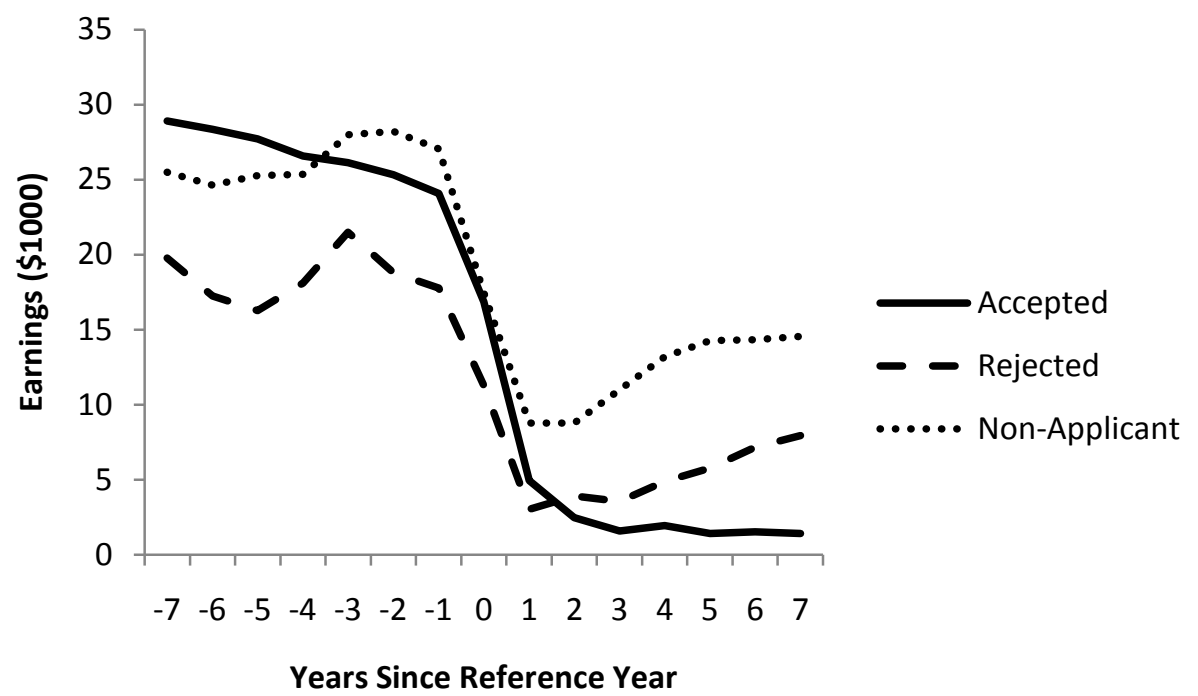

Panel A: Average Earnings

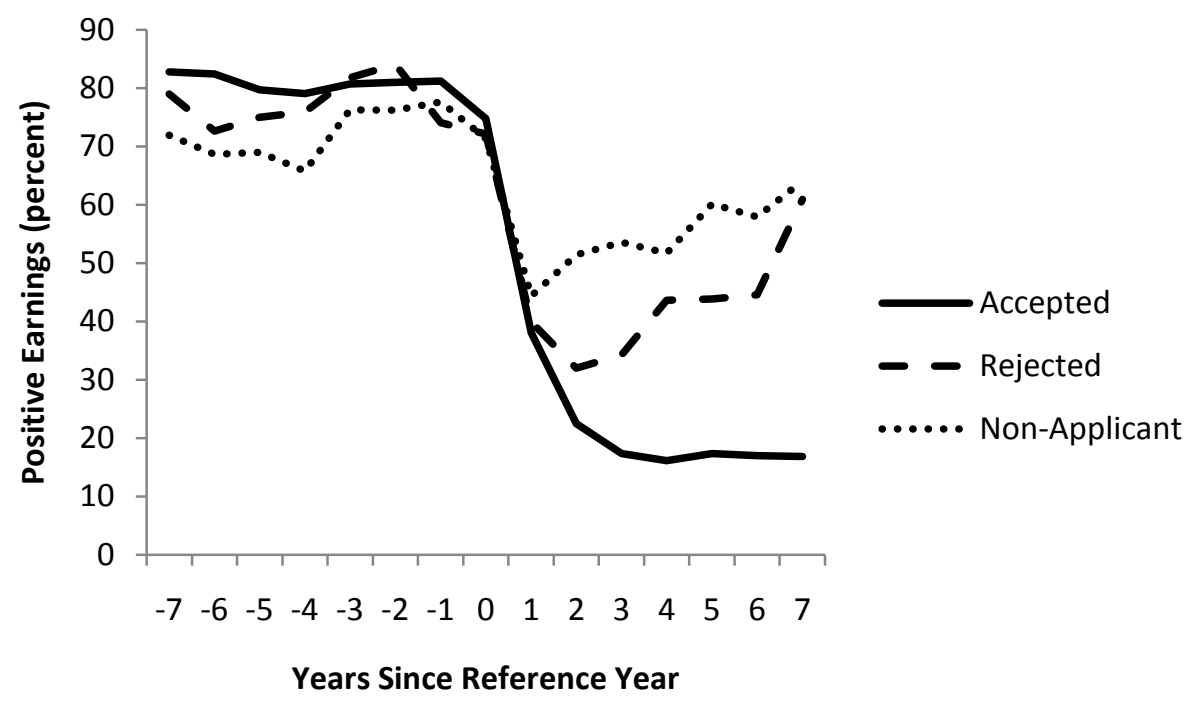

Panel B: Positive Earnings

Figure 7: Earnings by Disability Application and Receipt Status: Totally Disabled 

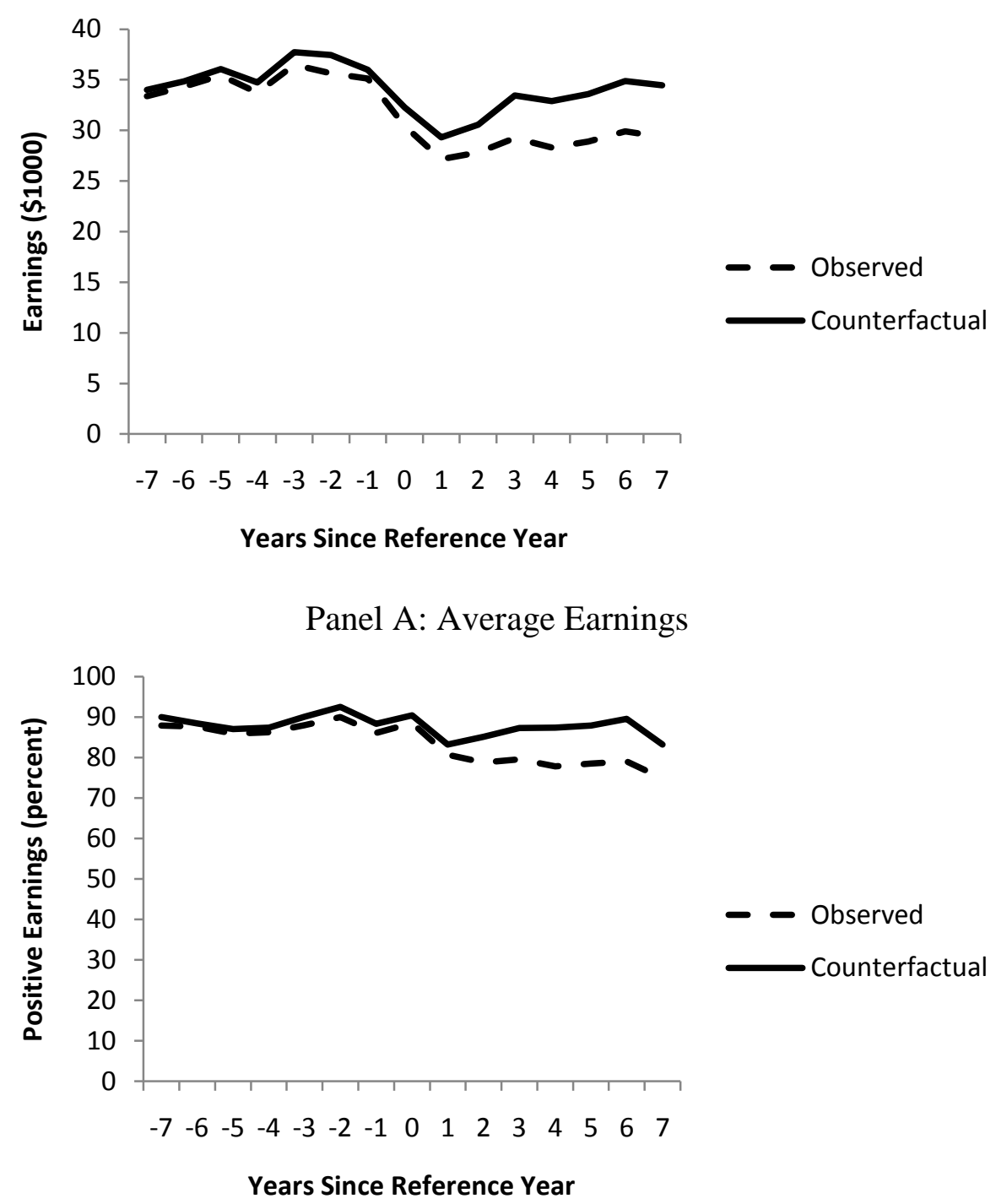

Panel B: Positive Earnings

Figure 8: Observed and Counterfactual Earnings of the Partially Disabled: Back and Spine Pain Counterfactual represents the upper bound of earnings of the partially disabled had none applied for disability benefits. 

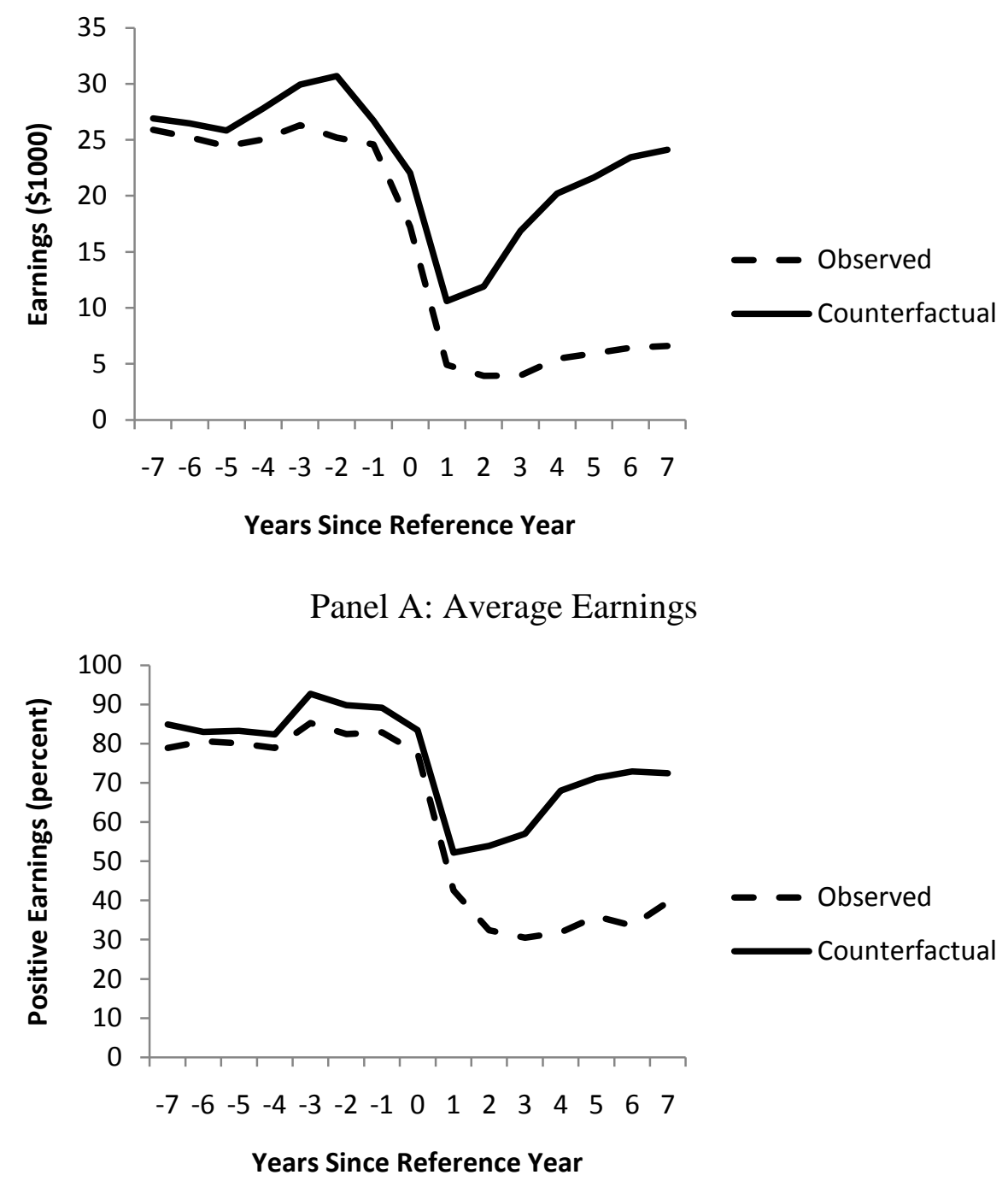

Panel B: Positive Earnings

Figure 9: Observed and Counterfactual Earnings of the Totally Disabled: Back and Spine Pain Counterfactual represents the upper bound of earnings of the partially disabled had none applied for disability benefits. 


\section{Table 1}

Data Summary by Disability Severity: Males ages 30 to 48

\begin{tabular}{|c|c|c|c|}
\hline & Non-Disabled & Partially Disabled & Totally Disabled \\
\hline \multirow{2}{*}{ Reference Age } & 40.0 & 41.1 & 42.2 \\
\hline & $(0.03)$ & $(0.21)$ & $(0.28)$ \\
\hline \multirow[t]{2}{*}{ High School } & 57.8 & 65.8 & 55.1 \\
\hline & $(0.26)$ & (1.5) & $(2.1)$ \\
\hline \multirow[t]{2}{*}{ College } & 30.8 & 13.6 & 7.1 \\
\hline & $(0.24)$ & (1.1) & (1.1) \\
\hline \multirow[t]{2}{*}{ White } & 86.9 & 86.5 & 73.6 \\
\hline & $(0.18)$ & $(1.1)$ & (1.9) \\
\hline \multirow[t]{2}{*}{ Married } & 73.6 & 68.8 & 61.5 \\
\hline & $(0.23)$ & (1.4) & $(2.1)$ \\
\hline \multirow[t]{2}{*}{ SSDI Insured } & 87.2 & 86.6 & 77.6 \\
\hline & $(0.18)$ & (1.1) & $(1.8)$ \\
\hline \multirow[t]{2}{*}{ SSDI Application } & 4.3 & 27.7 & 66.2 \\
\hline & $(0.11)$ & $(1.4)$ & $(2.0)$ \\
\hline \multirow[t]{2}{*}{ SSDI Receipt } & 2.7 & 17.5 & 55.4 \\
\hline & $(0.09)$ & $(1.2)$ & $(2.1)$ \\
\hline \multirow[t]{2}{*}{ SSDI or SSI Application } & 4.9 & 30.2 & 79.7 \\
\hline & $(0.11)$ & (1.4) & $(1.7)$ \\
\hline \multirow[t]{2}{*}{ SSDI or SSI Receipt } & 3.0 & 19.6 & 65.8 \\
\hline & $(0.09)$ & $(1.2)$ & $(2.0)$ \\
\hline \multirow[t]{2}{*}{ Accident } & - & 53.5 & 48.4 \\
\hline & & $(1.5)$ & $(2.1)$ \\
\hline \multirow[t]{2}{*}{ Working } & - & 95.0 & 90.1 \\
\hline & & $(0.67)$ & (1.3) \\
\hline \multirow[t]{2}{*}{ Work Accident } & - & 37.8 & 36.2 \\
\hline & & $(1.5)$ & $(2.0)$ \\
\hline \multirow[t]{2}{*}{ Dead within 7 Years } & 1.9 & 5.3 & 10.2 \\
\hline & $(0.07)$ & $(0.69)$ & $(1.3)$ \\
\hline Observations & 35724 & 1044 & 555 \\
\hline
\end{tabular}

Figures are computed from the Survey of Income and Program Participation, pooled over survey years 1990, 1991, 1992, 1993, and 1996. Totally disabled is defined as a one-year transition from being non-disabled to work-prevented; partially disabled is defined as a one-year transition from being non-disabled to work-limited, but a subsequent transition to being work-prevented is possible. The data do not include individuals disabled more than five years before the survey date. Married refers to marital status two years before the reference year. SSDI insured reflects insured status during the reference year. Application for and receipt of SSDI and SSI benefits is measured during the seven years before and after the reference year. 


\section{Table 2}

Dynamic Relationship between Disability and Earnings

\begin{tabular}{|c|c|c|c|c|}
\hline \multirow[b]{2}{*}{$\begin{array}{l}\text { Years Since } \\
\text { Disability }\end{array}$} & \multicolumn{2}{|c|}{ Partially Disabled } & \multicolumn{2}{|c|}{ Totally Disabled } \\
\hline & $\begin{array}{c}\text { Fixed-Effect } \\
\text { Estimate }\end{array}$ & $\begin{array}{c}\text { Standard } \\
\text { Error }\end{array}$ & $\begin{array}{c}\text { Fixed-Effect } \\
\text { Estimate }\end{array}$ & $\begin{array}{c}\text { Standard } \\
\text { Error }\end{array}$ \\
\hline & \multicolumn{4}{|c|}{ Panel A: Earnings } \\
\hline-7 & 2.0 & $0.99 *$ & 4.7 & $1.1^{* *}$ \\
\hline-6 & 1.2 & 0.9 & 3.7 & $1.0 * *$ \\
\hline-5 & 2.0 & $0.90 *$ & 3.1 & $0.98 * *$ \\
\hline-4 & 1.3 & $0.79 *$ & 2.2 & $0.84 * *$ \\
\hline-3 & 1.6 & $0.69 *$ & 2.6 & $0.77 * *$ \\
\hline-2 & 1.2 & $0.48 * *$ & 1.4 & $0.61^{*}$ \\
\hline \multicolumn{5}{|l|}{-1} \\
\hline 0 & -4.4 & $0.58 * *$ & -7.7 & $0.66 * *$ \\
\hline 1 & -7.7 & $0.78 * *$ & -18.5 & $0.95 * *$ \\
\hline 2 & -8.1 & $0.84 * *$ & -19.9 & $1.0 * *$ \\
\hline 3 & -8.3 & $1.0 * *$ & -19.9 & $1.0 * *$ \\
\hline 4 & -9.6 & $0.95 * *$ & -18.8 & $1.1 * *$ \\
\hline 5 & -9.3 & $0.95 * *$ & -18.7 & $1.1 * *$ \\
\hline 6 & -8.5 & $1.0 * *$ & -17.9 & $1.1^{* *}$ \\
\hline \multirow[t]{2}{*}{7} & -8.9 & $1.0 * *$ & -17.1 & $1.1 * *$ \\
\hline & \multicolumn{4}{|c|}{ Panel B: Positive Earnings } \\
\hline-7 & -0.7 & 1.3 & 1.6 & 2.1 \\
\hline-6 & -0.5 & 1.4 & -0.3 & 2.3 \\
\hline-5 & 0.0 & 1.3 & -1.9 & 2.2 \\
\hline-4 & -0.3 & 1.2 & -3.1 & 1.9 \\
\hline-3 & 0.2 & 1.0 & 0.7 & 1.8 \\
\hline-2 & 1.6 & 0.8 & 1.1 & 1.6 \\
\hline-1 & & & & \\
\hline 0 & 0.5 & 0.9 & -5.7 & $1.7 * *$ \\
\hline 1 & -6.0 & $1.3 * *$ & -39.6 & $2.5^{* *}$ \\
\hline 2 & -7.7 & $1.4 * *$ & -49.2 & $2.5^{* *}$ \\
\hline 3 & -8.4 & $1.5 * *$ & -51.2 & $2.6 * *$ \\
\hline 4 & -10.5 & $1.6 * *$ & -50.7 & $2.6 * *$ \\
\hline 5 & -10.9 & $1.7 * *$ & -48.2 & $2.7 * *$ \\
\hline 6 & -10.5 & $1.7 * *$ & -48.1 & $2.8^{* *}$ \\
\hline 7 & -12.4 & $1.7 * *$ & -43.7 & $2.7 * *$ \\
\hline
\end{tabular}

The earnings estimates are derived from an individual fixed-effects model. The model includes year fixed effects, age, age squared, and the interactions of age and age squared with race, education, and marital status. * and ** indicate significance at the five and one percent level. 
Table 3

Data Summary by Disability Application and Receipt Status: Disabled Males ages 30 to 48

\begin{tabular}{|c|c|c|c|}
\hline & Accepted & Rejected & Non-Applicants \\
\hline \multirow[t]{2}{*}{ Reference Age } & 43.5 & 39.9 & 40.6 \\
\hline & $(0.27)$ & $(0.47)$ & $(0.23)$ \\
\hline \multirow[t]{2}{*}{ High School } & 54.7 & 66.7 & 66.0 \\
\hline & $(2.1)$ & $(3.5)$ & $(1.6)$ \\
\hline \multirow[t]{2}{*}{ College } & 7.5 & 3.5 & 15.6 \\
\hline & (1.1) & (1.4) & $(1.3)$ \\
\hline \multirow[t]{2}{*}{ White } & 76.5 & 77.1 & 86.8 \\
\hline & $(1.8)$ & $(3.1)$ & (1.2) \\
\hline \multirow[t]{2}{*}{ Married } & 63.9 & 60.3 & 69.2 \\
\hline & $(2.0)$ & $(3.6)$ & $(1.6)$ \\
\hline \multirow[t]{2}{*}{ SSDI Insured } & 83.4 & 84.5 & 83.1 \\
\hline & (1.6) & $(2.7)$ & $(1.3)$ \\
\hline \multirow[t]{2}{*}{ Totally Disabled } & 64.6 & 41.4 & 13.6 \\
\hline & $(2.0)$ & $(3.6)$ & $(1.2)$ \\
\hline \multirow[t]{2}{*}{ Accident } & 40.1 & 62.9 & 57.2 \\
\hline & $(2.0)$ & $(3.6)$ & $(1.7)$ \\
\hline \multirow[t]{2}{*}{ Working } & 91.8 & 93.0 & 94.4 \\
\hline & $(1.1)$ & (1.9) & $(0.79)$ \\
\hline \multirow[t]{2}{*}{ Work Accident } & 28.3 & 49.3 & 40.6 \\
\hline & (1.9) & $(3.7)$ & $(1.7)$ \\
\hline \multirow[t]{2}{*}{ Dead within 7 Years } & 12.8 & 4.0 & 3.7 \\
\hline & (1.4) & (1.4) & $(0.65)$ \\
\hline \multirow[t]{2}{*}{ Back or Spine Problem } & 29.4 & 44.2 & 37.4 \\
\hline & (1.9) & $(3.7)$ & (1.7) \\
\hline \multirow[t]{2}{*}{ Cancer } & 4.3 & 0.0 & 2.0 \\
\hline & $(0.84)$ & - & $(0.49)$ \\
\hline \multirow[t]{2}{*}{ Heart Trouble } & 10.7 & 5.5 & 8.6 \\
\hline & $(1.3)$ & $(1.7)$ & $(0.97)$ \\
\hline \multirow[t]{2}{*}{ High Blood Pressure } & 1.1 & 4.5 & 1.8 \\
\hline & $(0.44)$ & $(1.5)$ & $(0.46)$ \\
\hline \multirow[t]{2}{*}{ Chronic Kidney Problems } & 2.6 & 0.4 & 1.3 \\
\hline & $(0.67)$ & $(0.45)$ & $(0.39)$ \\
\hline \multirow[t]{2}{*}{ Stiffness or Deformity } & 2.1 & 4.5 & 8.9 \\
\hline & $(0.59)$ & $(1.5)$ & $(0.98)$ \\
\hline \multirow[t]{2}{*}{ Stroke } & 4.3 & 0.9 & 1.0 \\
\hline & $(0.85)$ & $(0.70)$ & $(0.34)$ \\
\hline Observations & 573 & 185 & 841 \\
\hline
\end{tabular}

See Table 1 for sample selection. 
Table 4

Upper-Bound Estimates of Disability Benefits on Earnings: Accepted Applicants

\begin{tabular}{|c|c|c|c|c|c|c|}
\hline \multirow[b]{2}{*}{$\begin{array}{l}\text { Years Since } \\
\text { Disability }\end{array}$} & \multicolumn{2}{|c|}{ Fixed-Effects } & \multicolumn{2}{|c|}{ Diff-in-Diffs } & \multicolumn{2}{|c|}{ Matching } \\
\hline & Estimate & $\begin{array}{l}\text { Standard } \\
\text { Error }\end{array}$ & Estimate & $\begin{array}{l}\text { Standard } \\
\text { Error }\end{array}$ & Estimate & $\begin{array}{c}\text { Standard } \\
\text { Error }\end{array}$ \\
\hline & \multicolumn{6}{|c|}{ A. Earnings } \\
\hline-7 & 5.5 & $1.4 * *$ & 3.3 & $1.7^{*}$ & 1.4 & 2.6 \\
\hline-6 & 3.3 & $1.0^{* *}$ & 1.6 & 1.4 & -0.7 & 2.2 \\
\hline-5 & 2.8 & $1.0^{* *}$ & 0.4 & 1.4 & -0.5 & 2.4 \\
\hline-4 & 1.7 & $0.84 *$ & 0.1 & 1.2 & -0.9 & 2.1 \\
\hline-3 & 1.1 & 0.8 & -1.2 & 1.1 & -3.4 & 2.1 \\
\hline-2 & 0.8 & 0.6 & -0.6 & 0.8 & -3.7 & 2.2 \\
\hline-1 & & & & & -3.6 & 2.2 \\
\hline 0 & -7.0 & $0.69 * *$ & -2.8 & $0.94 * *$ & -2.9 & 2.1 \\
\hline 1 & -16.9 & $0.97 * *$ & -9.9 & $1.3^{* *}$ & -5.0 & $1.9^{* *}$ \\
\hline 2 & -19.4 & $1.0^{* * *}$ & -12.7 & $1.4^{* * *}$ & -8.0 & $1.7 * *$ \\
\hline 3 & -20.7 & $1.0^{* * *}$ & -14.7 & $1.6^{* *}$ & -12.2 & $2.0 * *$ \\
\hline 4 & -21.1 & $1.1^{* *}$ & -14.5 & $1.5^{* *}$ & -15.1 & $2.1 * *$ \\
\hline 5 & -22.2 & $1.1^{* *}$ & -16.6 & $1.5^{* *}$ & -16.9 & $2.0 * *$ \\
\hline 6 & -22.2 & $1.1^{*}$ & -17.6 & $1.6^{* *}$ & -17.9 & $2.4^{* *}$ \\
\hline \multirow[t]{2}{*}{7} & -22.3 & $1.1^{* *}$ & -17.7 & $1.6^{* *}$ & -19.0 & $2.1 * *$ \\
\hline & \multicolumn{6}{|c|}{ A. Positive Earnings } \\
\hline-7 & 0.2 & 2.0 & -0.2 & 2.5 & 2.2 & 3.6 \\
\hline-6 & 1.2 & 1.9 & 2.7 & 2.5 & 3.3 & 3.5 \\
\hline-5 & -1.0 & 2.0 & -0.3 & 2.4 & 3.5 & 3.6 \\
\hline-4 & -1.6 & 1.7 & 0.3 & 2.2 & 3.0 & 3.3 \\
\hline-3 & -0.6 & 1.7 & -0.4 & 2.1 & -3.0 & 3.4 \\
\hline-2 & 0.7 & 1.5 & -0.5 & 1.8 & -0.6 & 3.6 \\
\hline-1 & & & & & -3.7 & 3.5 \\
\hline 0 & -4.1 & $1.5^{* *}$ & -4.0 & $1.9^{*}$ & -0.1 & 4.1 \\
\hline 1 & -33.0 & $2.4^{* *}$ & -25.5 & $2.8^{* * *}$ & -9.5 & 4.9 \\
\hline 2 & -44.4 & $2.5^{* *}$ & -37.9 & $2.9^{* *}$ & -24.2 & $4.7 * *$ \\
\hline 3 & -49.7 & $2.6^{* *}$ & -43.4 & $3.0^{* * *}$ & -32.2 & $4.7 * *$ \\
\hline 4 & -54.7 & $2.5^{* * *}$ & -48.2 & $3.0^{* * *}$ & -38.0 & $4.8^{* *}$ \\
\hline 5 & -55.2 & $2.5^{* *}$ & -50.1 & $3.0^{* * *}$ & -43.0 & $4.7 * *$ \\
\hline 6 & -56.7 & $2.6^{* *}$ & -52.7 & $3.0^{* * *}$ & -44.7 & $5.0^{* *}$ \\
\hline 7 & -59.3 & $2.4^{* *}$ & -56.2 & $2.9^{* *}$ & -51.5 & $4.6 * *$ \\
\hline
\end{tabular}

The difference-in-differences estimates are the difference of the fixed-effect estimates between the accepted and non-applicants; the matching estimates are derived from matching accepted applicants to non-applicants based on health, income, and demographic characteristics. * and ** indicate significance at the five and one percent level. 
Table 5

Upper-Bound Estimates of Disability Benefits on Earnings: Rejected Applicants

\begin{tabular}{|c|c|c|c|c|c|c|}
\hline \multirow[b]{2}{*}{$\begin{array}{l}\text { Years Since } \\
\text { Disability }\end{array}$} & \multicolumn{2}{|c|}{ Fixed-Effects } & \multicolumn{2}{|c|}{ Diff-in-Diffs } & \multicolumn{2}{|c|}{ Matching } \\
\hline & Estimate & $\begin{array}{l}\text { Standard } \\
\text { Error }\end{array}$ & Estimate & $\begin{array}{l}\text { Standard } \\
\text { Error }\end{array}$ & Estimate & $\begin{array}{c}\text { Standard } \\
\text { Error }\end{array}$ \\
\hline & \multicolumn{6}{|c|}{ A. Earnings } \\
\hline-7 & 2.0 & 1.9 & -0.2 & 2.1 & -3.4 & 2.0 \\
\hline-6 & 1.3 & 1.7 & -0.3 & 2.0 & -3.3 & 2.1 \\
\hline-5 & 1.0 & 1.5 & -1.3 & 1.8 & -3.1 & 2.0 \\
\hline-4 & 0.8 & 1.4 & -0.9 & 1.7 & -4.1 & $1.9^{*}$ \\
\hline-3 & 2.3 & $1.0^{*}$ & 0.0 & 1.3 & -3.8 & 2.0 \\
\hline-2 & 1.4 & 0.8 & 0.0 & 1.0 & -4.1 & $2.1^{*}$ \\
\hline-1 & & & & & -5.1 & $2.1 *$ \\
\hline 0 & -7.0 & $1.1^{* *}$ & -2.9 & $1.3^{*}$ & -6.6 & $2.0 * *$ \\
\hline 1 & -14.7 & $1.5^{* *}$ & -7.8 & $1.8^{* *}$ & -8.8 & $2.0^{* *}$ \\
\hline 2 & -14.3 & $1.6^{* *}$ & -7.6 & $1.8^{* *}$ & -10.5 & $2.3 * *$ \\
\hline 3 & -14.7 & $1.7 * *$ & -8.8 & $2.0 * *$ & -13.1 & $2.3^{* *}$ \\
\hline 4 & -13.6 & $1.7^{* *}$ & -7.0 & $2.0^{* *}$ & -13.4 & $2.5^{* *}$ \\
\hline 5 & -13.0 & $1.7^{* *}$ & -7.4 & $2.0^{* *}$ & -13.0 & $2.4^{* *}$ \\
\hline 6 & -11.9 & $1.8^{* *}$ & -7.3 & $2.1^{* *}$ & -12.9 & $2.3 * *$ \\
\hline \multirow[t]{2}{*}{7} & -11.1 & $1.7^{* *}$ & -6.5 & $2.0^{* *}$ & -13.6 & $2.5 * *$ \\
\hline & \multicolumn{6}{|c|}{ A. Positive Earnings } \\
\hline-7 & -1.4 & 3.7 & -1.8 & 4.0 & -3.1 & 4.4 \\
\hline-6 & -1.1 & 4.6 & 0.4 & 4.9 & -1.5 & 4.2 \\
\hline-5 & 0.6 & 4.0 & 1.3 & 4.3 & 0.1 & 4.1 \\
\hline-4 & 2.5 & 3.6 & 4.4 & 3.8 & 0.6 & 3.6 \\
\hline-3 & 6.2 & $2.1 * *$ & 6.4 & $2.4 * *$ & 0.6 & 3.6 \\
\hline-2 & 4.9 & $2.0 *$ & 3.7 & 2.3 & 0.4 & 4.2 \\
\hline-1 & & & & & -4.9 & 4.1 \\
\hline 0 & -1.4 & 2.3 & -1.2 & 2.6 & 2.3 & 4.4 \\
\hline 1 & -17.7 & $3.9 * *$ & -10.2 & $4.2^{*}$ & -2.7 & 5.1 \\
\hline 2 & -26.2 & $4.1^{* *}$ & -19.6 & $4.4^{* *}$ & -13.0 & $5.1 * *$ \\
\hline 3 & -21.2 & $4.8^{* *}$ & -14.9 & $5.1^{* *}$ & -12.2 & $5.3^{*}$ \\
\hline 4 & -16.4 & $4.2 * *$ & -9.9 & $4.5^{*}$ & -6.7 & 5.6 \\
\hline 5 & -17.0 & $4.2^{* *}$ & -12.0 & $4.5^{* *}$ & -12.5 & $5.7^{*}$ \\
\hline 6 & -16.5 & $4.6^{* *}$ & -12.5 & $4.9^{*}$ & -12.3 & $5.4^{*}$ \\
\hline 7 & -12.0 & $4.3 * *$ & -8.9 & 4.6 & -8.2 & 5.6 \\
\hline
\end{tabular}

The difference-in-differences estimates are the difference of the fixed-effect estimates between the rejected and non-applicants; the matching estimates are derived from matching rejected applicants to non-applicants based on health, income, and demographic characteristics. * and ** indicate significance at the five and one percent level. 


\section{Table 6}

Interval Regression Estimates (in \$1000)

\begin{tabular}{lcc} 
& Coefficients & Std. Error \\
\cline { 2 - 3 } Disabled & & \\
Post & 1.9 & 3.9 \\
Disabled*Post & 2.6 & 3.8 \\
Age & -14.7 & $3.6^{* *}$ \\
Age Squared & 5.5 & $0.13^{* *}$ \\
White & -0.06 & $0.0019^{* *}$ \\
High School & 13.0 & $0.33^{* *}$ \\
Diploma & & \\
College Degree & 19.6 & $0.46^{* *}$ \\
Married & 46.9 & $2.7^{* *}$ \\
Constant & 13.0 & $0.77^{* *}$ \\
& -128.2 & $5.6^{* *}$ \\
B. Variance & & \\
Disabled & & \\
Post & -1.2 & $0.24^{* *}$ \\
Disabled*Post & -0.15 & 0.25 \\
Constant & 0.25 & 0.26 \\
\hline
\end{tabular}

The sample is restricted to the non-disabled and disabled non-applicants. $* *$ indicates significance at the one percent level. 


\section{RECENT WORKING PAPERS FROM THE CENTER FOR RETIREMENT RESEARCH AT BOSTON COLLEGE}

The Treatment of Married Women by the Social Security Retirement Program Andrew G. Biggs, Gayle L. Reznik, and Nada O. Eissa, November 2010

What is the Impact of Foreclosure on Retirement Security?

Irena Dushi, Leora Friedberg, and Anthony Webb, November 2010

Children and Household Utility: Evidence from Kids Flying the Coop

Norma B. Coe and Anthony Webb, November 2010

Overview of the CRR 2009 Retirement Survey

Alicia H. Munnell, Norma B. Coe, Kelly Haverstick, and Steven A. Sass, Octobre 2010

State Wage-Payment Laws, the Pension Protection Act of 2006, and 401(k) Saving Behavior

Gary Engelhardt, October 2010

Asset Cycles and the Retirement Decisions of Older Workers Jan Ondrich, October 2010

Price Deflators, the Trust Fund Forecast, and Social Security Solvency Barry Bosworth, October 2010

The Impact of a DROP Program on the Age of Retirement and Employer Pension Costs Samson Alva, Norma B. Coe, and Anthony Webb, September 2010

Housing Consumption in Late Life: The Role of Income, Health Shocks, and Marital Shocks

Douglas A. Wolf and Janet M. Wilmoth, September 2010

Adjusting Social Security for Increasing Life Expectancy: Effects on Progressivity Courtney Monk, John A. Turner, and Natalia A. Zhivan, August 2010

Work and Retirement Patterns for the G.I. Generation, Silent Generation, and Early Boomers: Thirty Years of Change

Richard W. Johnson, Barbara A. Butrica, and Corina Mommaerts, July 2010

Spousal Health Shocks and the Timing of the Retirement Decision in the Face of ForwardLooking Financial Incentives

Courtney Harold Van Houtven and Norma B. Coe, June 2010

Incorporating Employee Heterogenity Into Default Rules for Retirement Plan Selection Gopi Shah Godi and Colleen Flaherty Manchester, May 2010

All working papers are available on the Center for Retirement Research website (http://crr.bc.edu) and can be requested by e-mail (crr@bc.edu) or phone (617-552-1762). 